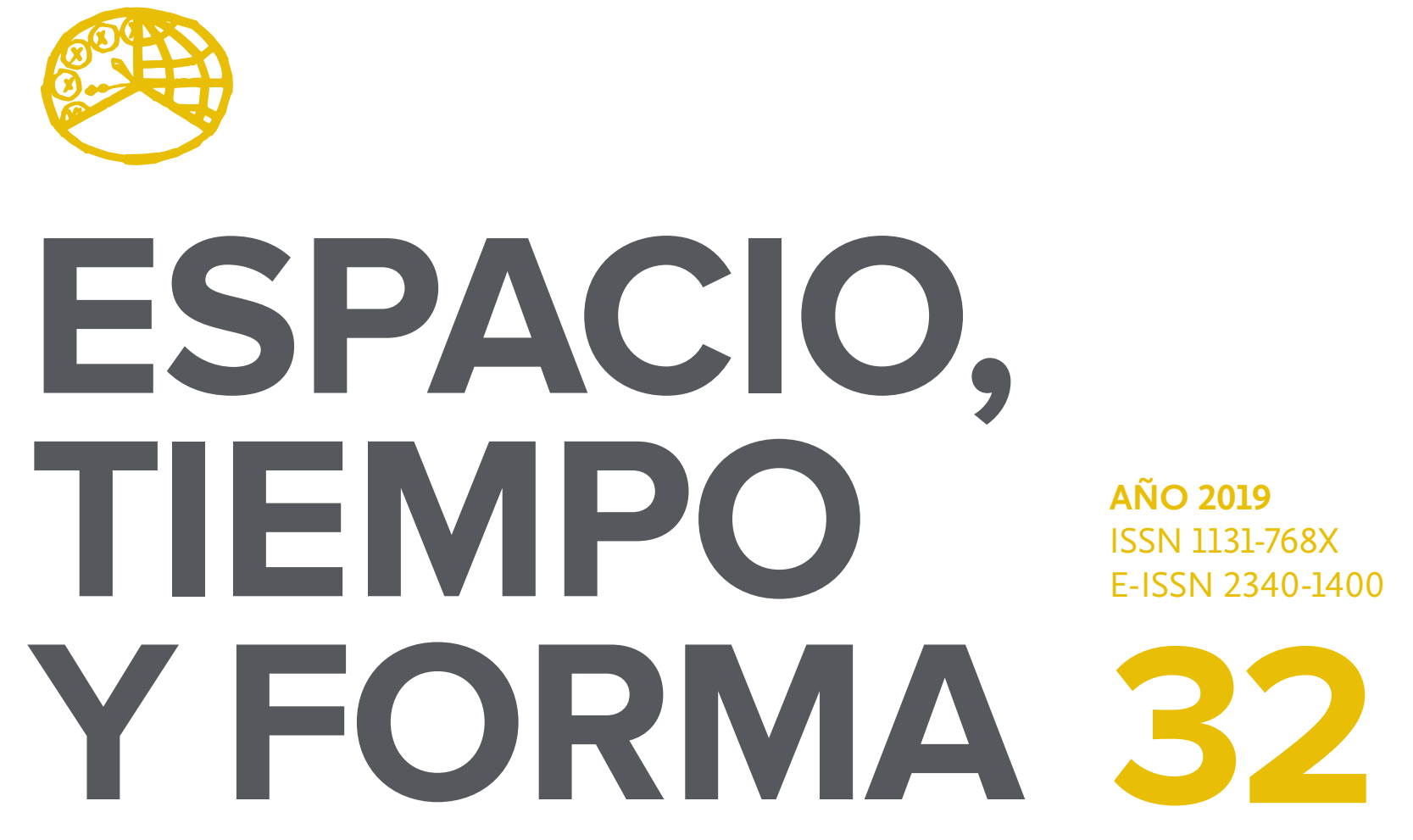

SERIE IV HISTORIA MODERNA

REVISTA DE LA FACULTAD DE GEOGRAFÍA E HISTORIA 




AÑO 2019

ISSN 1131-768X

E-ISSN 2340-1400

SERIE IV HISTORIA MODERNA

REVISTA DE LA FACULTAD DE GEOGRAFİA E HISTORIA

DOI: http://dx.doi.org/10.5944/etfiv.32.2019

\section{UกED}

UNIVERSIDAD NACIONAL DE EDUCACIÓN A DISTANCIA 
La revista Espacio, Tiempo y Forma (siglas recomendadas: ETF), de la Facultad de Geografía e Historia de la UNED, que inició su publicación el año 1988, está organizada de la siguiente forma:

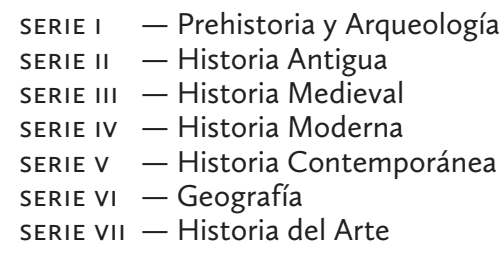

Excepcionalmente, algunos volúmenes del año 1988 atienden a la siguiente numeración:

$$
\begin{aligned}
& \mathrm{N}^{\circ} 1 \text { - Historia Contemporánea } \\
& \mathrm{N}^{\circ} 2 \text { - Historia del Arte } \\
& \mathrm{N}^{\circ} 3 \text { - Geografía } \\
& \mathrm{N} .^{\circ} 4 \text { - Historia Moderna }
\end{aligned}
$$

ETF no se solidariza necesariamente con las opiniones expresadas por los autores.

\author{
UNIVERSIDAD NACIONAL DE EDUCACIÓN A DISTANCIA \\ Madrid, 2019 \\ SERIE IV · HISTORIA MODERNA N. ${ }^{\circ} 32,2019$ \\ ISSN 1131-768X · E-ISSN 2340-1400 \\ DEPÓSITO LEGAL \\ M-21.037-1988 \\ URL \\ ETF IV · HISTORIA MODERNA · http://revistas.uned.es/index.php/ETFIV \\ DISEÑO Y COMPOSICIÓN \\ Carmen Chincoa Gallardo · http://www.laurisilva.net/cch \\ Impreso en España · Printed in Spain
}

(c) (1) (8) Esta obra está bajo una licencia Creative Commons Reconocimiento-NoComercial 4.0 Internacional. 


\section{MONOGRÁFICO · SPECIAL ISSUE}

POLIITICA IMPERIAL Y ADMINISTRACIÓN DE

INDUSTRIAS ESTRATÉGICAS: LA ARMADA

ESPAÑOLA EN EL LARGO SIGLO XVIII

IMPERIAL POLICY AND STRATEGIC INDUSTRY

ADMINISTRATION: THE SPANISH NAVY IN

THE LONG EIGHTEENTH CENTURY 



\title{
NAVÍOS PARA UN IMPERIO GLOBAL: LA CONSTRUCCIÓN NAVAL Y LA MATRÍCULA DE MAR EN ESPAÑA, AMÉRICA Y FILIPINAS DURANTE EL LARGO SIGLO XVIII (1670-1834)
}

\author{
WARSHIPS FOR A GLOBAL EMPIRE: SHIPBUIDLING \\ AND THE MARITIME REGISTRY IN SPAIN, \\ AMERICA AND THE PHILIPPINES DURING THE \\ LONG EIGHTEENTH CENTURY (1670-1834)
}

\author{
Iván Valdez-Bubnov ${ }^{1}$ \\ Recibido: 26/06/2018 - Aceptado: 06/08/2018 \\ Doi: http://dx.doi.org/10.5944/etfiv.2019.22245
}

\begin{abstract}
Resumen
El presente estudio tiene el propósito de analizar la política industrial desarrollada por la monarquía hispánica para la producción de buques de guerra durante un largo siglo XVIII comprendido entre I670 y I834. Su hipótesis fundamental es que una de las claves para completar nuestro conocimiento sobre la naturaleza de los sistemas administrativos de la construcción naval es la relación del Estado y la iniciativa empresarial con la mano de obra especializada, encuadrada en el marco normativo de la Matrícula de Mar. Esta línea interpretativa intersecta con el debate historiográfico dedicado a la alternativa asiento/administración directa como clave para comprender la importancia de la construcción naval en el proceso de construcción del Estado moderno. La conexión se encuentra en que la tendencia legislativa de la corona consistió, primero, en militarizar la mano de obra especializada por medio de la inclusión en la matrícula y, posteriormente, en concentrar los contratos de construcción naval exclusivamente en individuos matriculados. Esto representa una diferencia estructural entre el contratista de principios del siglo XVIII, encargado de una multiplicidad de procesos productivos, y aquél de finales de la centuria, responsable únicamente de la movilización y administración de una mano de obra previamente militarizada. De manera paralela, este estudio busca integrar la dimensión asiática de la construcción naval española,
\end{abstract}

1. Instituto de Investigaciones Históricas/Universidad Nacional Autónoma de México. C. e.: ivanvaldezbubnov@ yahoo.com

Este estudio se ha realizado como parte del proyecto PAPIIT IG400318 de la Universidad Nacional Autónoma de México (UNAM), titulado: Redes empresariales y administración estatal: la producción de materiales estratégicos en el mundo hispánico como escenario de la globalización temprana. 
no de manera tangencial, sino como un componente fundamental y prioritario del reformismo borbónico en las industrias estratégicas.

\title{
Palabras clave
}

Construcción naval; matrícula de mar; maestranza; asiento; administración directa; Filipinas.

\begin{abstract}
The purpose of the present article is to outline the industrial policies developed by the Spanish Monarchy for the production of warships during the long Eighteenth century (1670-I834), in Spain, America and the Philippines. Its main hypothesis is that an important element to complete our understanding of the administrative systems of Spanish naval shipbuilding is the relationship between the State, the entrepreneurs dedicated to this aspect of the armaments industry, and the specialised workforce recruited through the registry of maritime professions known as Matrícula de Mar. This line of argumentation intersects with the historiographical debate dedicated to understand the State-building process of imperial Spain through the two main administrative methods employed in its armaments industries (private contracting and direct state administration). The Matrícula de Mar allowed the Spanish crown to create new militarised corporations of shipbuilding workers and, from the last third of the Eighteenth century it followed a consistent policy of concentrating the shipbuilding contracts on small-scale entrepreneurs belonging to these corporations. This had important implications for the meaning of the alternative between private contracting and direct state administration. The article also details the peculiarities of shipbuilding administration in Spanish America and Asia, through the expansion of the Matrícula de Mar.
\end{abstract}

\section{Keywords}

Naval shipbuilding; Matrícula de Mar; dockyard workforce; private contracting; State administration; Philippines. 


\section{INTRODUCCIÓN METODOLÓGICA}

El presente estudio tiene por objetivo esbozar una perspectiva imperial de las políticas empresariales y laborales desarrolladas por la corona española para producir buques de guerra durante el largo siglo XVIII. El primer tema de su competencia, la naturaleza de los métodos administrativos empleados por la corona para el desarrollo de la construcción naval, ha sido objeto de una tradición historiográfica que se remonta a la segunda década del siglo XIX ${ }^{2}$, y que alcanzó sus rasgos definitorios durante el último tercio del siglo $\mathrm{XX}^{3}$. En años recientes, estos temas han sido abordados por varios historiadores, en una línea de análisis dedicada a comprender la dimensión empresarial de la construcción naval y su relación con la infraestructura administrativa del Estado ${ }^{4}$. En sus manifestaciones culminantes, esta línea ha trascendido la noción previamente establecida de una radical dicotomía entre la producción por administración estatal directa y por medio de contratas -también llamadas asientos- con empresarios particulares, enfatizando, a un mismo tiempo, el pragmatismo de las aparentemente oscilantes decisiones gubernamentales en este aspecto central de las industrias de armamentos ${ }^{5}$. El presente artículo tiene como punto de partida las conclusiones previamente establecidas por estos autores.

El segundo tema de su competencia, el estudio de los mecanismos para la movilización de mano de obra dedicada a la construcción naval, ha sido objeto de análisis comparativamente menos detallados. En efecto, nuestro conocimiento del gremio de maestranza, aunque hunde también sus raíces historiográficas en el siglo XIX, ha sido casi siempre comprendido como un componente (y no el más importante) del desarrollo de los registros estatales para la movilización de las poblaciones marítimas: la Matrícula de Mar $^{6}$. Así, la historia de la Matrícula ha sido regularmente estudiada desde el punto de vista de las poblaciones sujetas al servicio del Estado como marinería militar: un componente esencial del poder naval, ciertamente, pero no relacionado, al menos de manera directa, con la producción de buques de guerra. Así, tanto la notable sofisticación de los estudios recientes sobre la matrícula ${ }^{7}$, como la existencia previa de trabajos dedicados a las corporaciones encargadas de la administración o de la dirección técnica de la construcción naval, no han incidido de manera equivalente en nuestros conocimientos acerca de la importancia de la maestranza ${ }^{8}$ para el desarrollo de la construcción naval por administración directa y por contrata. La hipótesis fundamental del presente estudio es que una de las claves para completar nuestro conocimiento sobre la naturaleza de

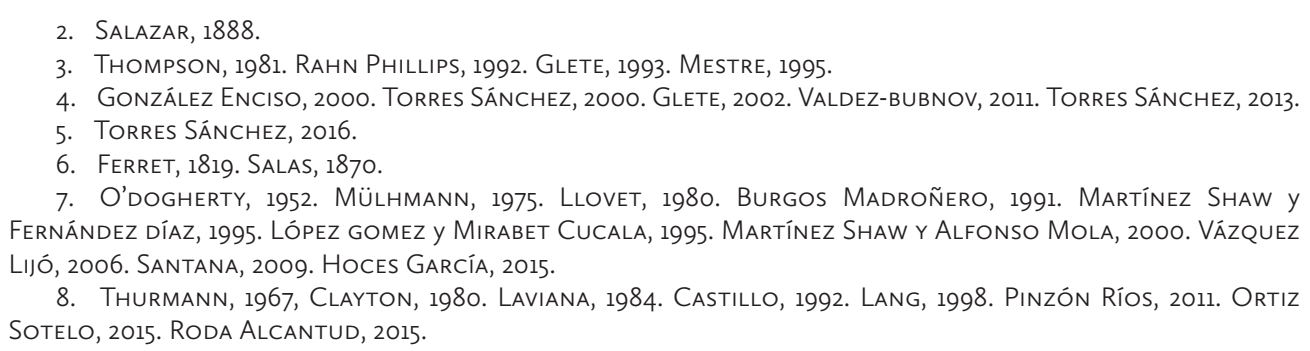


los sistemas administrativos de la construcción naval es, precisamente, la relación del Estado y la iniciativa empresarial con la mano de obra especializada, encuadrada en el marco administrativo de la Matrícula de Mar. La posibilidad de desarrollar un análisis exhaustivo de este gremio, así como su relación con las cofradías de mareantes previamente existentes, se encuentra fuera de los alcances -y también de los objetivos- de este espacio. Sin embargo, si la presente síntesis interpretativa logra hacer evidente que la maestranza matriculada es un elemento relevante para comprender la naturaleza de los sistemas administrativos de la construcción naval o, en otras palabras, que la línea de análisis dedicada a las implicaciones políticas y empresariales de la alternativa asiento/administración directa no se encuentra todavía completa sin esta perspectiva, entonces habrá cumplido su cometido principal.

Existe otra ambición primigenia que es preciso expresar aquí. La historiografía de la construcción naval es desigual, también, desde el punto de vista de los estudios regionales, con una tradición a un tiempo longeva y actualizada al respecto de la construcción de buques en la España peninsular, recientemente equiparada en detalle y complejidad por la atención vertida a la producción en la isla de $\mathrm{Cuba}^{\mathrm{io}} \mathrm{y}$, en una menor medida, a la de otros astilleros americanos de envergadura comparativamente reducida $^{\text {II }}$. En contraste, la historia de la construcción naval española en Asia, principalmente en Filipinas, es regularmente omitida, o apenas mencionada, por los esfuerzos llevados a cabo para escribir narrativas globales sobre la construcción naval. Sin embargo, la Real Armada tenía su razón de ser en la protección de las vías de comunicación marítima del Imperio español, el cual hundía sus raíces en Europa, América y Asia, e hizo posible la articulación del primer sistema mercantil propiamente global de la modernidad. Por ende, un estudio de la construcción naval a nivel imperial requiere, necesariamente, integrar la perspectiva asiática, no de manera tangencial y exógena, sino como un componente fundamental y prioritario del reformismo borbónico en las industrias estratégicas. Integrar esta dimensión en un análisis estructural sobre el desarrollo administrativo de la construcción naval, basado en la interacción entre el Estado, la iniciativa empresarial y la mano de obra es, precisamente, el segundo objetivo del presente estudio ${ }^{\mathrm{I2}}$.

Es necesario hacer una última precisión metodológica. La historia de la construcción hispana de buques de guerra en la época clásica de la navegación a vela puede ser comprendida a partir de dos grandes ciclos, situados entre los siglos XVI y XIX. Estos dos ciclos, cada uno definido por características técnicas y administrativas específicas, son en apariencia divididos por el cambio dinástico entre las casas de Habusburgo y de Borbón, iniciado en I70o. Sin embargo, desde un punto de vista tecnológico y administrativo, ambos aparecen conectados por un periodo de transición que abarcó, aproximadamente, desde 1670 hasta década de $\mathrm{I}_{730^{13}}$. El inicio de este período de

9. Una primera aproximación a esta perspectiva en VALDEZ-BUBNOV, 2018

10. Serrano, 2008

11. Martinez Shaw y Alfonso Mola, 2005

12. Para la perspectiva administrativa y tecnológica de la construcción naval en Filipinas: VALDEZ-BUBNOV, $2017 \mathrm{~B}$.

13. Para la justificación tecnológica y administrativa de esta cronología: VALDEZ-BUBNOV, 2009B. 
transición señala el principio de nuestro largo siglo XVIII. Su final, situado en I834, queda definido por la última reglamentación expedida por la corona para definir los métodos administrativos de la construcción naval en los arsenales del Estado.

\section{LA POLÍTICA DE CONSTRUCCIÓN NAVAL DE LA DINASTÍA HABSBURGO EN EUROPA, AMÉRICA Y ASIA HASTA 1700: SIINTESIS ADMINISTRATIVA Y TECNOLÓGICA}

El primer ciclo en la historia de la construcción naval hispana corresponde a la consolidación de la dinastía Habsburgo, y a la creación del primer sistema centralizado de comercio global, basado en el establecimiento regular de los convoyes de la Carrera de Indias (I52I) y la Carrera de Filipinas (I57I). Este ciclo estuvo caracterizado por una tensión constante entre los objetivos estratégicos de la corona, definidos por la necesidad de hacer uso del mar para fines bélicos, y los objetivos del comercio marítimo a nivel imperial, definidos por dos influyentes grupos de interés mercantil, basados en el puerto fluvial de Sevilla, en el caso del Atlántico, y en las ciudades de México y Manila, en el caso del Pacífico. También estuvo definido por un importante nivel de autonomía operativa por parte de las élites regionales dedicadas a la construcción naval, así como por la casi inexistencia (a excepción del Mediterráneo) de una infraestructura material permanente (astilleros/ arsenales), perteneciente a la corona. Esto tuvo como resultado niveles relativamente reducidos de intervención estatal en los procesos productivos, usualmente definidos por relaciones contractuales con empresarios particulares, financiadas por la corona y supervisadas por sus oficiales, conocidos, en este contexto, como superintendentes. Los contratos (asientos) eran, en muchos casos, empresas escasamente redituables, en parte debido a las constantes dificultades padecidas por la Real Hacienda para depositar a tiempo las cantidades acordadas con el empresario, pero también a las variaciones de costos y al rigor de los oficiales reales en las labores de cuenta y razón. En consecuencia, las operaciones de construcción naval eran con frecuencia realizadas por empresarios interesados en otro tipo de compensación por parte de la corona, tales como el ascenso en la jerarquía nobiliaria, la explotación de otras fuentes de riqueza, o la obtención de licencias para participar en el comercio transatlántico. Las responsabilidades del empresario podían varíar según las especificaciones del contrato, aunque normalmente incluían la mayor parte de los procesos productivos: corta, arrastre y salazón de maderas; compra o producción de manufacturas (salvo artillería y armamento); movilización y administración de mano de obra, y operaciones de astillero. Las variantes solían estar definidas por el grado de terminación de la obra, parcial o total, así como por la cantidad de pertrechos provistos por la Real Hacienda. Así, las operaciones de astillero podían ser concluidas por medio la administración directa de la corona, ya por designio previo, ya por incapacidad del contratista. En algunos casos específicos, la construcción podía ser llevada a cabo enteramente por administración directa, es decir, sin pasar por un contrato (definido como una suma de procesos productivos bajo control empresarial). Sin embargo, se trataba de procesos industriales complejos, 
destinados a producir la maquinaria bélica más sofisticada de su tiempo, y que incluso la administración directa total comprendía necesariamente la interacción con diversos empresarios encargados de proveer determinados productos o servicios, a distintos niveles. En efecto, los contratos incluían regularmente, entre los diversos rubros que especificaban las responsabilidades del empresario, la movilización asalariada de obreros y operarios. Estas cláusulas normalmente especificaban los costos del trabajo asalariado en el contexto general de la obra, para su aprobación o supervisión por parte de los oficiales de la corona, y no especificaban en ningún caso la naturaleza de las relaciones contractuales entre el asentista y los trabajadores. Éstas eran reguladas por medio de procedimientos en principio consuetudinarios, pero progresivamente definidos y sistematizados por la reglamentación generada por asociaciones de trabajadores de carácter local: las cofradías o gremios $^{\mathrm{I4}}$. Se trataba de organizaciones de naturaleza asistencial, usualmente constituidas en torno a una advocación religiosa, las cuales actuaban como mecanismo de protección de privilegios y derechos de las poblaciones marítimas ante otros sectores sociales, y ante la administración pública. Usualmente reúnian a los practicantes de las profesiones marítimas de una comunidad determinada, especialmente marineros y pescadores, pero también prácticos de la construcción naval y de otras artes, generando una relativa capacidad de representación política por medio de la elección de sus propios oficiales. También ejercían determinadas facultades de protección y asistencia social, financiadas por medio del cobro de cuotas y derechos entre sus cófrades o agremiados. Existe una importante historiografía ${ }^{15}$ dedicada a las cofradías de mareantes de los centros tradicionales de construcción naval en la península ibérica, especialmente en las Cuatro Villas y las provincias de Vizcaya y Guipúzcoa, y aquí nos limitaremos a señalar la intersección de estas formas corporativas con el desarrollo de la intervención estatal sobre los procesos relacionados con la producción de buques de guerra.

Desde el punto del vista tecnológico, es importante considerar que la interacción entre intereses públicos y privados, propia de la industria de la construcción naval, funcionaba en el marco de una legislación concebida para asegurar que los intereses estratégicos de la corona -y en segunda instancia, de los grupos de interés mercantil asociados con ella- quedasen plasmados en la concepción técnica de los buques $^{16}$. Esto derivó en la creación de ordenanzas técnicas basadas en la definición de las medidas y proporciones de distintos tipos de navío, y alcanzó su forma más lograda con la edición de I6ı8, la cual, con algunas añadiduras, estuvo vigente para todos los reinos hispánicos hasta I72I. La combinación de estos elementos tuvo por efecto que los navíos estuviesen concebidos, no solo como vehículos de comercio, sino también como instrumentos de poder naval del Estado, siendo capaces de servir indistintamente tanto en las flotas de Indias como en las armadas reales, lo cual sucedió en repetidas ocasiones. La enorme importancia de los

14. Para una introducción historiográfica al tema: GonZÁlez ENCISO, 1998: 111-137. MoLAS, 2000: 47-62.

15. Segura Obrero, 1987. Erkoreka, 1991. Tena García, 1995. García fernández, 2004. Solórzano Tellechea, 2011. Serna Vallejo, 2016. Rahn Phillips, 2017.

16. FERNÁNDEZ IZQUIERDO, 1989: 54-58. 
intereses mercantiles en el desarrollo técnico de la construcción naval tuvo un efecto restrictivo sobre los tonelajes permitidos por esta legislación, tanto en el Atlántico como en el Pacífico, aunque los motivos, en cada caso, fueron diferentes. En el caso del sistema atlántico, el orígen de este fenómeno se encontraba en la barra de San Lúcar, el somero paso fluvial que conducía al puerto de Sevilla, sede de la Casa de Contratación, órgano rector del comercio trasatlántico. Esta limitación geográfica condujo a importantes restricciones al calado: el porte máximo de los navíos autorizados por las ordenanzas de i6ı8 para la inclusión en la carrera de Indias era de 624 tonleadas, lo que correspondía al tipo de 50 cañones en dos baterías completas. Esta restricción provocó, prácticamente desde el establecimiento de la Carrera, que se permitiese la utilización de la bahía de Cádiz para el ancoraje de capitanas, almirantas, y otros navíos grandes (las mismas Ordenanzas establecían los portes de éstos ligeramente por encima de las Iooo toneladas). Esta dualidad portuaria creaba dificultades para la fiscalización de una proporción importante del comercio trasatlántico. En el mismo sentido, el tesoro proveniente de las minas americanas era trasportado, precisamente, en los buques más grandes, lo cual facilitaba la filtración de plata fuera de registro. Todo ello condujo al desarrollo de una élite mercantil basada en Cádiz, en creciente rivalidad con los intereses de Sevilla, la cual, para el último tercio del siglo XVII, comenzó a constituir un fuerte factor de presión política para la reforma del sistema transatlántico. Existe vasta evidencia documental señalando que ambos grupos de interés formulaban parte de sus discursos en términos técnicos y geográficos, ambos directamente relacionados con el tonelaje autorizado de los navíos. Así, durante el último tercio del siglo XVII, la legislación de construcción naval se convirtió en un asunto de vital importancia para la reforma del comercio transatlántico ${ }^{17}$. Ante las sucesivas añadiduras a las ordenanzas de i6ı8, autorizando la construcción de navíos de mayor porte, los intereses sevillanos intentaron contrarrestar su desventaja geográfica por medio de ambiciosos proyectos de dragado de la barra, así como por un intento, en I69I, de reformar las Ordenanzas para hacer posible que todos los tipos de navío remontasen el Guadalquivir sin peligro ${ }^{18}$. Durante este período, la corona resolvió sus necesidades navales, en parte, recurriendo a alianzas con otras potencias ${ }^{19}$, pero también fomentando la construcción por empresarios privados en los centros navieros del norte de la Península Ibérica. Así, a partir de la década de i68o se botaron varios navíos de guerra de portes superiores a los autorizados por la legislación, cuyas características técnicas no diferían substancialmente de los navíos de línea entonces producidos por los rivales europeos de la monarquía hispana.

Pese a la constante presión militar por parte de la Francia de Luis XIV, así como a las dificultades financieras padecidas en la construcción naval en la Península Ibérica, durante este período se construyeron suficientes buques para la protección del comercio transatlántico y las rutas internas del Caribe, en La Habana y

\footnotetext{
17. VALDEZ-BubnOV, 2009a.

18. VALDEZ-BUBNOV, 2011.

19. STORRS, 2006.
} 
Campeche. La protección del tráfico de cabotaje en el Pacífico americano, por otra parte, se efectuaba con buques construidos por una compleja interacción de intereses públicos y privados, en Centroamérica -la zona de Realejo- ${ }^{20}$ y en Perú -los astilleros de Guayaquil ${ }^{21}$. Como en la Carrera de Indias, el principal estímulo para la participación empresarial en la construcción de navíos era la posibilidad de tomar parte en el comercio regional. Esto convirtió a estos astilleros, particularmente el segundo, en importantes focos de producción privada, con frecuencia por comisión del Consulado de Comerciantes de Lima ${ }^{22}$. También se construyeron allí buques de mayor porte para la Armada del Mar del Sur, pertenenciente al Virreinato del Perú. Estos procesos iniciaban con una comisión por parte del virrey a un gobernador local, denominado corregidor, quien delegaba su autoridad en un superintendente, el cual podía ser un oficial a sueldo, o un empresario detentor de un contrato para determinadas obras, usualmente operaciones de corta, labra y arraste de maderas $^{23}$. Para este fin, el superintendente imponía trabajo forzado a las poblaciones indígenas bajo la autoridad del corregidor. La movilización de trabajadores podía ser también contratada con un empresario especializado en ese rubro, usualmente perteneciente a las mismas comunidades indígenas ${ }^{24}$, lo cual no alteraba la naturaleza forzosa del servicio. Este mecanismo representaba, en sí mismo, un negocio privado vinculando a la administración local con las estructuras de poder indígenas ${ }^{25}$. Las operaciones de astillero eran dirigidas por un constructor bajo sueldo, así como por diversos oficiales subalternos, algunos especializados en procesos específicos, como carpinteros de ribera, de blanco, calafates, etc. Todo ello dio lugar al crecimiento de una importante mano de obra especializada en la construcción naval ${ }^{26}$. Esta nueva maestranza, distinta de la importada de España ${ }^{27}$, se hallaba organizada en cofradías locales, y estaba usualmente compuesta por mestizos y castas libres, aunque el trabajo esclavo era también utilizado en los astilleros ${ }^{28}$. La totalidad de las operaciones podía ser tomada bajo contrato por un colono local a cambio de determinadas mercedes, como la asignación de un corregimiento. Finalmente, los productos manufacturados importados de España y Europa, tales como los herrajes y, en determinados casos, lonas y jarcia, eran provistos a cuenta del virreinato desde el arsenal del $\mathrm{Callao}^{29}$, donde podían ser comprados por el empresario en turno, en el caso de una contrata, o entregados al superintendente como parte de los procedimientos por administración directa. Existen indicios de que los navíos construidos en esta zona no seguían la legislación de construcción naval vigente desde i6i8. En muchos casos se trataba de buques de grandes dimensiones, desde




400 hasta más de iooo toneladas, aunque sus características técnicas continúan siendo casi totalmente desconocidas para la historiografía ${ }^{30}$.

En el caso de la vertiente asiática del sistema de construcción naval del Pacífico, la restricción oficial al crecimiento de los tonelajes, definitoria, como hemos visto, de la construcción naval atlántica, operó de manera análoga a lo largo de todo este período. La corona también buscó proteger los intereses del comercio sevillano a través de la legislación de construcción naval ${ }^{\mathrm{BI}}$, en este caso, ante la creciente competencia representada por los comerciantes de la ciudad de México y sus agentes en Manila ${ }^{32}$. Es importante recordar que el objetivo último de la expansión atlántica española había sido alcanzar las islas de la especiería y los desarrollados centros económicos de lejano oriente ${ }^{33}$. Para finales del siglo XVI, la colonización de América y el descubrimiento de las rutas de la navegación transpacífica habían hecho posible que la plata extraída de Nueva España y el Perú pagase un creciente volumen de mercancías asiáticas, que comenzaron a vulnerar la posición dominante del comercio sevillano sobre los mercados coloniales ${ }^{34}$. Tras un período exploratorio inicial, en el cual tuvo un rol protagónico la construcción naval en las costas occidentales de la Nueva España y Centroamérica ${ }^{35}$, la ruta transpacífica comenzó a utilizar navíos construidos en las islas Filipinas ${ }^{36}$. Esto fue posible gracias a su abundancia en maderas de alta calidad ${ }^{37}$, así como a la permanencia de estructuras de poder tradicionales (Barangays), que permitían la movilización temporal de mano de obra indígena (polo) bajo la autoridad de sus propios caciques (cabezas de Barangay) $)^{8}$. Estos últimos operaban bajo la autoridad de oficiales españoles: los alcaldes mayores asignados a la provincia en que se efectuaran las operaciones de corte, arrastre y labra de maderas, o los corregidores, cuando se trataba de espacios fronterizos. La interacción con las autoridades indígenas era llevada a cabo por diversos rangos de oficiales madereros (cabos, ahiladores y mandadores), mientras que la dimensión técnica de las operaciones de astillero se encontraba bajo la autoridad de maestros constructores, usualmente procedentes de Vizcaya y Guipúzcoa ${ }^{39}$, quienes, desde el último tercio del siglo XVII, se hallaban constituidos en juntas para determinar las características técnicas de los buques ${ }^{40}$. La construcción naval también se benefició de la imposición de tributo en especie y compras forzadas (vandalas) a las poblaciones indígenas, lo que hizo posible aprovechar una gran variedad de productos manufacturados esenciales para la industria, especialmente jarcia y lonas hiladas con fibras locales, y diversos materiales de calafatería ${ }^{4 \mathrm{I}}$. Tanto la movilización de mano de obra como

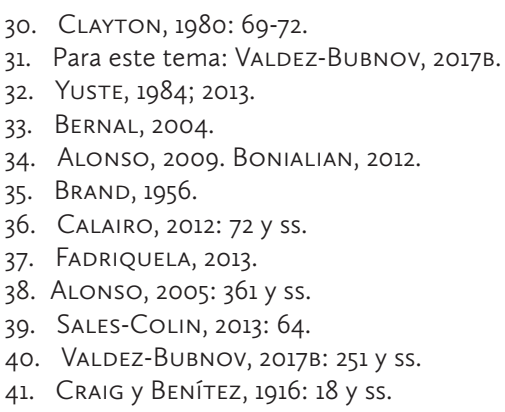


la obtención de materias primas y productos de manufactura local, eran posibles en función de la existencia de la doble institución de la encomienda -la asignación de determinadas comunidades indígenas a la autoridad de un colono españoly el repartimiento -la movilización de poblaciones o de sus recursos para obras públicas o privadas (denominación española del polo) ${ }^{42}$. De esto se deriva que la encomienda/repartimiento era el marco jurídico que hacía posible la movilización de recursos humanos y materiales para la construcción naval, vinculando, tal como en el caso del Perú, a diversos rangos de la administración española con las estructuras de poder indígenas. Es necesario considerar también que, como en aquél caso, el principal estímulo para participar en la construcción naval consistía, desde los oficiales madereros hasta el mismo gobernador, en el privilegio de ser considerado en la repartición de las toneladas de carga de las flotas que operaban entre Manila y Acapulco ${ }^{43}$. Esto hace explícito el vínculo entre el régimen de la encomienda, la administración pública, el comercio transpacífico, y la construcción naval en Filipinas.

Otro factor importante para explicar el florecimiento de la construcción naval española en Asia fue la presencia, desde una etapa temprana, de importantes comunidades extrajeras en la bahía de Manila, principalmente chinas y japonesas, las cuales no sólo contaban con técnicos especializados en la producción de diversos herrajes, sino que también actuaban como representantes de un importante comercio de importación proveniente de sus respectivos países ${ }^{44}$. La corona promulgó diversas iniciativas para transferir la responsabilidad de los cortes madereros a estas comunidades ${ }^{45}$ lo cual, empero, nunca representó un contrapeso efectivo al trabajo indígena. En todo caso, el vínculo mercantil y manufacturero representado por estos grupos se traducía en precios ventajosos en relación con las importaciones europeas conducidas a través de Nueva España, lo cual vulneraba los intereses del comercio transatlántico. Más aún, el comercio entre Manila y Acapulco, consistente en productos suntuarios y materias primas para la industria textil, inundaba con regularidad los mercados de Nueva España y el Perú, generando una constante, aunque no necesariamente eficaz, presión administrativa y fiscal por parte de la corona. Tal como en el caso del sistema atlántico, en el Pacífico también existía una fuerte presión naval por parte de los rivales mercantiles de la monarquía Habsburgo, ingleses y holandeses, además de una casi permanente guerra de corso librada por diversos protagonistas asiáticos ${ }^{46}$.

Como resultado de esta combinación de factores mercantiles y militares, la corona promulgó una legislación tecnológica diseñada, no sólo para estandarizar las capacidades bélicas -ofensivas y defensivas- de los navíos que efectuaban la Carrera de Filipinas, sino también para limitar su capacidad de carga, en aras de proteger los intereses del comercio sevillano. Así, a lo largo de todo el siglo XVII

42. Hidalgo Nuchera, 1995: 55-81.

43. Archivo General de Indias (en adelante AGI) FILIPINAS, 94, $n^{\circ} .113$.

44. BJORK, 2009: 25 y ss.

45. CUMMINS, 1974: 198.

46. BOXER, 1985: 419 y ss. 
estuvo vigente un reglamento que limitaba el tonelaje de los navíos de la Carrera del Pacífico a tan sólo 200 toneladas, con el señalamiento específico que la capacidad de carga debía corresponder a la construcción del buque. Sin embargo, tal como en el caso del conflicto Sevilla-Cádiz, los intereses del comercio incidieron, desde una fecha muy temprana, en importantes incrementos al tonelaje real de los navíos en servicio. En efecto, estos tuvieron un vertiginoso salto desde 400 y 500 toneladas, en la década de I580, hasta I 400 en I628, y I600 para mediados de siglo. También existen indicios tempranos de la existencia de navíos de hasta 2000 toneladas. El enorme contraste entre los límites impuestos por la legislación y las prácticas de la construcción naval es una muestra más de las tensiones económicas, políticas y militares expresadas en el diseño de los navíos, y demuestra la existencia de una flagrante desobediencia tecnológica por parte de los intereses novohispano-filipinos. Sin embargo, la tendencia al incremento del tonelaje de los navíos del Pacífico español no se mantuvo de manera constante a lo largo de toda la centuria. Aunque existen indicios de construcciones de 2000 toneladas todavía hasta mediados de siglo, para I67I el porte más común se había reducido a sólo 700, remontando otra vez a 800-900 toneladas para $1696^{47}$. Aún bajo esta luz, resulta evidente que la legislación de construcción naval del Pacífico, diseñada para la defensa de su ruta principal, pero, también, para la protección de los intereses del comercio sevillano, resultaba ineficaz ante la influencia de los mercaderes de México y Manila, vinculados, a través del comercio, con los encomenderos y los oficiales responsables de las operaciones de astillero en torno a la bahía de Manila ${ }^{48}$.

\section{LA ADMINISTRACIÓN DE LA CONSTRUCCIÓN NAVAL DE LA MONARQUÍA BORBÓNICA DESDE UNA PERSPECTIVA IMPERIAL: LOS REINADOS DE FELIPE V Y FERNANDO VI (1700-1754)}

En I70o, al morir el rey Carlos Il, la dinastía Habsburgo se extinguió en España, dando lugar a la coronación de Felipe V y, con ello, a la Guerra de Sucesión Española (I700-I7I4). Esta aparentemente clara división cronológica ha hecho menos evidente la continuidad estructural en la política tecnológica y administrativa de ambos dinastías, la cual, como veremos más adelante, se mantuvo cuando menos hasta la década de I730 y, el Pacífico, hasta mediados del siglo XVIII. La percepción de discontinuidad generada por el cambio dinástico se ha visto acentuada por las dificultades coyunturales padecidas por la nueva monarquía durante los años de guerra. Durante este difícil periodo inicial, el rey Felipe V sólo pudo disponer de cinco navíos de su propiedad, de los cuales tres fueron comprados. En estos años, el comercio imperial se mantuvo gracias a la colaboración de la Marina francesa ${ }^{49}$,

47. VALDEZ-Bubnov, 2017B: 246-250.

48. Para una sugerente visión de este problema hacia finales del siglo XVII: CALvo, 2016: 65-90.

49. Para una visión actualizada de este proceso: SERrANo, 2011: 289 Y 290-291. 
la cual escoltó los convoyes de la carrera del Atlántico, e hizo posible cierta penetración mercantil de ese país en la carrera del Pacífico. Esto ha creado la imagen de una crisis de producción en los centros tradicionales de construcción naval de la Península Ibérica, heredada del gobierno de los Habsburgo. Sin embargo, los astilleros de Cantabria, Vizcaya y Guipúzcoa se encontraron activos durante la década de i69o, y lo estarían nuevamente durante la década de i7ıo, lo cual indica que tan sólo se vieron brevemente paralizados por el efecto disruptor de la guerra ${ }^{50}$.

Felipe $\mathrm{V}$ demostró poseer, desde el inicio mismo de su reinado, una visión estratégica de carácter verdaderamente global. La primera medida administrativa de su reinado en el ámbito de la construcción naval estuvo dedicada al Pacífico, y precede cuando menos en una década a cualquiera de las dedicadas al Atlántico. La tensión política entre la corona y las élites mercantiles de México y Manila continuó operando, en el paso del siglo XVII al XVIII, como factor decisivo en la construcción naval en Filipinas. La legislación vigente, que autorizaba un porte máximo de tan sólo 200 toneladas por navío, había sido actualizada por el gobierno del último Habsburgo en I697 y I699, elevándolo a 300 ${ }^{5 \mathrm{I}}$. Durante esos años, los prácticos de la construcción naval en la bahía de Manila fijaron el porte de los navíos entre 800 y 900 toneladas. En I702, Felipe V promulgó un nuevo reglamento que cancelaba los anteriores, aumentando el porte autorizado de los navíos a 500 toneladas, y también el valor de las mercancías transportadas desde Filipinas a Nueva España ${ }^{52}$. Esto representó el mayor incremento oficial al tonelaje desde el establecimiento de la Carrera del Pacífico. Sin embargo, como había sucedido antes, este reglamento no fue obedecido. Los prácticos resolvieron que el porte mínimo no debía ser menor a 800 toneladas, argumentando que la duración de la travesía de Manila a Acapulco hacía necesario que dos terceras partes de la capacidad de carga estuviesen dedicadas al transporte de víveres y agua. Así, durante las primeras dos décadas del siglo XVIII, los astilleros filipinos continuaron botando, en flagrante desobediencia de la nueva legislación borbónica, navíos de 800 y más toneladas ${ }^{53}$.

Por otra parte, en el Atlántico, el fin gradual de la guerra señaló la reactivación de la construcción naval. Los pedidos de la corona a los astilleros españoles se iniciaron a partir de I7I2, y sus operaciones fueron dirigidas por una nueva generación de superintendentes de construcción: Antonio de Gaztañeta y Joseph del Llano, en Cantabria y Vizcaya, así como Joseph Patiño y Joseph del Campillo en Cataluña. La construcción naval en América debía tener un rol preponderante, pues el principal plan de producción estaba basado en La Habana, Cuba. Se trataba de un programa de construcción de io navíos de 60 cañones, bajo medidas y planos de Gaztañeta. Estos buques debían prestar servicio en las rutas caribeñas (específicamente, en la antigua Armada de Barlovento), y en la protección de los convoyes de la Carrera de Indias. Debían ser construidos por medio de un contrato con Manuel López Pintado, supervisado por oficiales de la corona, y provisto de recursos financieros por las cajas

50. Castañedo Galán, 2001: 94-97. Valdez-Bubnov, 2011: 91-95, 140, 276-277. TORRes SáncheZ, 2016: 22,138 y SS.

51. VALDEZ-BUBNOV, 2017B: 250.

52. YUSTE, 2007: 36-38. BARRIO MUÑOZ 2012: 233, 248.

53. VALDEZ-BubnOV, 2017B: 251. 
de México, así como por la asignación temporal de las rentas de cruzada y azogue. Las maderas provendrían de cortes locales, pero también de la Florida, y de Veracruz. Pese a todo ello, las demandas logísticas de la fase final de la guerra, específicamente, el sitio de Barcelona en I7I3-I4, impidieron la realización del proyecto.

Los principales astilleros tradicionales de la Península Ibérica (Guarnizo, Zorroza, Orio, Pasajes, Rentería y San Feliú de Guixols) comenzaron a producir, entre I7I3 y I7I6, nuevas series de navíos destinados sostener una política exterior expansiva, concebida para recuperar las posesiones italianas perdidas en la paz de Utrecht (I7I4). La construcción de estos buques hizo posible, en I7I6 y I7I7, el armamento de vastas operaciones anfibias para la recuperación de Sicilia y Cerdeña. Es importante señalar que las nacientes fuerzas navales de Felipe V se vieron también aumentadas por un número importante de navíos comprados en el extranjero, así como por medio del antiguo expediente del embargo, o la contratación forzosa de buques pertenecientes a empresarios particulares ${ }^{54}$. Así, las características estructurales del sistema naval heredado de los Habsburgo se encontraban todavía plenamente operativas, haciendo posible ejecutar una ambiciosa estrategia de expansión militar. Empero, el desastre de Cabo Passaro (I7I6) y el conflicto internacional resultante de la expansión mediterránea (la Guerra de la Cuádruple Alianza, I7I8-I9), tuvieron un efecto negativo sobre el programa de rearmamento naval. En el primer episodio se perdieron varios navíos y, en el segundo, un ejército francés destruyó varios todavía en grada.

Durante este período tuvo lugar una serie de reformas administrativas que cambiaron la estructura del sistema naval atlántico. El 2I de febrero de I7I4, la corona decretó la creación de la Real Armada, aboliendo parcialmente el sistema de armadas regionales. Sin embargo, las escuadras de galeras del Meditérráneo, la Armada de Barlovento y la Armada del Mar del Sur continuaron vigentes hasta fines de la década de I740, aunque con niveles de fuerza fluctuantes y relativamente reducidos.Varios navíos construidos en Cuba, Veracruz, Realejo y Guayaquil prestaron servicio en las armadas americanas, aunque estas también contaron, en tiempos de guerra, con la presencia de buques y escuadrones completos de la Real Armada.

En I7I7 tuvieron lugar otras tres medidas decisivas para la industria de la construcción naval. La primera constistió en el establecimiento de una estructura administrativa derivada de la ordenanza francesa de I689, basada en dos corporaciones principales, el Cuerpo General, o los oficiales destinados al mando operativo de los buques (formados, a partir de ese año, en la nueva Academia de Guardias Marinas de Cádiz) y el Cuerpo de Ministerio, los oficiales dedicados a la contaduría y administración a bordo de los navíos, así como en los puertos y astilleros reales. La segunda medida fue la promulgación de un reglamento concebido para cuantificar y definir las profesiones relacionadas con el uso del mar5s. Por Real Decreto de 28 de enero se estableció un registro voluntario de todas las profesiones marítimas,

54. TORRES SÁNCHEZ, 2016: 141.

55. Existió un antecedente, la Ordenanza de 31 de octubre de 1625, la cual ordenaba que se formara una «matrícula general» de todas las profesiones marítimas. No tuvo continuidad administrativa. SALAS, 1870: 108-112 
particularmente la marinería y los oficios técnicos relacionados con la construcción naval ${ }^{56}$. Se trata de una reforma que tendría continuidad administrativa a lo largo de todo del siglo XVIII, y que, posteriormente, estaría relacionada con la capacidad de la corona para movilizar grupos empresariales e invervenir los procesos productivos de la construcción naval en España y, como veremos más adelante, también en América y en Filipinas. El 23 de noviembre de ese mismo año, Gaztañeta expidió un reglamento pare censar las profesiones náuticas en la provincia de Guipúzcoa, el cual incluía carpinteros de ribera y de blanco, calafates, aserradores, toneleros, herreros, barrenadores y cordeleros ${ }^{57}$.

La tercera medida decisiva del año I7I7 fue la transferencia de la Casa de Contratación de Sevilla a Cádiz. Esto representó una toma de partido por parte del gobierno de Felipe $\mathrm{V}$ en el ya añejo conflicto entre ambas ciudades y tuvo trascendentales efectos sobre la industria de la construcción naval ${ }^{8}$. En efecto, los partidarios de Cádiz lograron que la corona aprobase en I72I (y publicase en I722), una importante reforma a las Ordenanzas de construcción naval. Se trata de las célebres Proporciones de las más essempciales, de Antonio de Gaztañeta, quien, como hemos visto, había sido responsable, entre I7II y I7I2, de la definición técnica de los navíos de 60 cañones concebidos para el malogrado contrato cubano de Manuel López Pintado, y también, como superintendente, había sido responsable de la construcción de varios navíos de ese mismo porte en Cantabria y Vizcaya entre i7I2 y i7I6. Aunque el título del reglamento de Gaztañeta expresa que se trataba de navíos de guerra, la Real Cédula que lo precede en la edición señala claramente que esos buques debían ser construidos por empresarios de todo el Imperio, para su servicio como mercantes en las flotas de Indias, sin que hubiese diferencia de fábrica, y sin que se siguiesen otras medidas o proporciones cualesquiera. Esto significa que, pese a la aparente especialización presente en su título, la legislación de Gaztañeta representa una importante confirmación tecnológica de la continuidad con el sistema de construcción naval del período Habsburgo. Es un error difundido en la historiografía suponer que se trata de navíos de línea en un sentido equivalente a los entonces producidos bajo ese nombre por otras potencias atlánticas.

El ascenso de Patiño al cargo de Secretario de Marina e Indias, en I726, señaló el inicio de la creación de una nueva infraestructura material altamente centralizada, concebida, de manera explícita, para generalizar el uso la administración directa total como método dominante en la producción de buques de guerra ${ }^{59}$. En ese año, la Península Ibérica fue dividida en tres Departamentos navales, cuyas capitales -Cádiz, Ferrol y Cartagena- debían contar con una base portuaria permanente, destinada a la producción y almacenamiento de pertrechos para el mantenimiento de los navíos en servicio operativo. Además, estas capitales departamentales debían contar, dentro de sus instalaciones, de astilleros para la construcción de navíos en grandes series estandarizadas, las cuales debían producirse por administración directa

56. VÁZQUEZ LIJÓ, 2006: 244.

57. SALAS, 1870: 152-153.

58. VALDEZ-BubNOV, 2009A: 2009B

59. «Construcción de Astilleros en Cádiz», Archivo Histórico Nacional (en adelanteAHN), Estado, 3208, Exp. 345. 
bajo la dirección de los oficiales del Cuerpo de Ministerio. El proyecto de Patiño, según sus propias palabras, era crear una Marina «económicamente dirigida y gobernada», concentrando tanto la construcción naval como la producción de materiales estratégicos en una vasta infraestructura portuaria de carácter permanente, financiada y administrada directamente por la corona ${ }^{60}$. Este proyecto no fue unánimemente aceptado, pues el mismo Gaztañeta emitió un duro dictamen en su contra, enfatizando la congruencia económica de continuar construyendo por contrata en los astilleros tradicionales, como se había hecho siempre ${ }^{6 .}$. Gaztañeta predijo las dificultades financieras de construir por administración directa en lugares que no solamente requerían de una fuerte inversión previa, sino que también se hallaban apartados de los centros productivos que, tradicionalmente, habían representado el fundamento económico de la construcción naval en España ${ }^{62}$. Sus críticas no tuvieron efecto. Como muestra de la viabilidad del proyecto estatal, en 1729 se botó al agua en Cádiz el navío Hércules, de 6o cañones, desde las instalaciones de su nuevo arsenal en construcción. Sin embargo, las grandes series de navíos que Patiño esperaba construir por administración directa en las tres capitales departamentales representaban tan sólo una posibilidad todavía distante en el futuro.

A partir de 1728 , una nueva generación de técnicos de orígen francés comenzó a dirigir la construcción naval en los nacientes astilleros departamentales. El más importante, Ciprian Autran, inició su actividad en Cádiz como capitán de Maestranza, y estuvo, junto con Jean Belletrande, relacionado con la botadura del ya mencionado Hércules ${ }^{63}$. Se trata de un punto importante, pues, como hemos visto, el censo y movilización de la maestranza era un aspecto prioritario dentro del esfuerzo gubernamental por controlar la industria de la construcción naval, en función del proyecto centralizador de Patiño. La conexión entre ambos elementos resulta clara, pues en 1726 se habían actualizado la órdenes de registro de marinería y maestranza originalmente expedidas en I7I7. Esta nueva versión de la ahora oficialmente llamada Matrícula de Mar establecía el alistamiento por clases, definidas según la profesión (marínería y oficios relacionados con la construcción). También concedía privilegios específicos a cambio del registro, tales como el fuero de Marina y la exención de determinadas contribuciones, aunque manteniendo todavía un carácter voluntario ${ }^{64}$.

Este paso hacia la militarización de las profesiones técnicas de la construcción naval, requisito para su movilización por parte del Estado, contribuye a explicar los primeros ensayos para producir por administración directa en el naciente arsenal de Cádiz. Por otra parte, los arsenales de Cartagena y Ferrol, aunque también establecidos en términos administrativos desde I726, tardaron más de veinte años en comenzar la producción regular de navíos en sus propias instalaciones, debido a la dificultad de financiar el desarrollo de sus respectivas infraestructuras. Como

\footnotetext{
60. VALDEZ-BUBNOV, 2011: 198-202.

61. «Parecer de dn. Antonio de Gaztañeta sobre el proyecto de Marina de Patiño», AHN, Estado, 3208, Exp. 345

62. Este tema está desarrollado en: VALDEZ-BUBNOV, 2011: 203-204.

63. QuinTERO GONZÁLEZ, 2004:13, 15, 95, 103, 119, 227-228.

64. VÁZQUEZ LIJÓ, 2006: 95.
} 
han demostrado Juan Castañedo Galán y Rafael Torres Sánchez, los principales centros de construcción naval para la Real Armada continuaron siendo, durante toda la primera mitad del siglo XVIII, los tradicionales astilleros del norte de la Península Ibérica (incluyendo Santoña, cerca de Guarnizo, y La Graña, cerca de Ferrol). Así, durante este período, los astilleros tradicionales operaron con un nivel comparativamente reducido de inversión estatal, en comparación con los arsenales departamentales, pero botaron al agua la mayor parte de los navíos de la Real Armada. Esto fue posible gracias a la continuidad de la práctica de contratar con empresarios pariculares, supervisados, como en el antiguo sistema de los Habsburgo, por funcionarios de la corona. También se compró un número importante de navíos. Todo ello indica, como han señalado los ya mencionados autores, que la corona siguió una política industrial pragmática a lo largo de todo este período, dentro de la cual la construcción por administración directa representaba apenas uno de los mecanismos para obtener navíos para la Real Armada, y no necesariamente el más productivo. Desde esta perspectiva, resultan claros los fundamentos de la oposición de Gaztañeta al proyecto centralizador de Patiño. Pese a ello, la administración directa total, tal como fue definida en I724, continuó siendo un objetivo estratégico de la monarquía, como demuestran las subsecuentes medidas para el control de la maestranza, así como la inversión -sostenida, aunque sujeta a altibajos- en la infraestructura permanente de los tres Departamentos navales de la Península Ibérica.

Aunque el proyecto de Patiño no contemplaba la construcción naval en la isla de Cuba, en este período inicial también se estableció un astillero en La Habana, donde se nombró a un capitán de Maestranza -Juan de Acosta- desde i722. Esto hizo posible iniciar allí, en I724, la construcción por administración directa de cuatro buques, bajo la dirección de un oficial del Cuerpo de Ministerio, Juan Pinto. Tal como ocurrió en España, la construcción por este sistema fue pronto sustituida por nuevos contratos con la iniciativa empresarial, personificada ahora por el mismo Acosta y sus vínculos personales con la élite empresarial habanera. En I73I, el capitán de Maestranza tomó bajo contrato la construcción de cuatro navíos en el astillero La Habana. La concentración de funciones en la persona de Acosta es un indicador importante de la imbricación progresiva del sistema de producción por adminsitración directa y por asiento, efecutada a través del progresivo control sobre la mano de obra de astillero ${ }^{65}$. El contrato de Acosta es importante también en otro sentido: fue precisamente a través de él que los conceptos de polivalencia mercantil y militar, presentes todavía en los diseños de Gaztañeta, comenzaron a abandonarse en favor de la especialización bélica. En efecto, el contrato produjo una serie de cuatro navíos de 60 cañones, bautizados como Los Cuatro Continentes, los cuales presentaban, no sólo un importante aumento del tonelaje en relación con los tipos correspodientes de las Proporciones de las más essempciales, sino también un incremento en la potencia de fuego por medio de la extensión de la batería principal en una porta. Estas son caractarísticas análogas a las desarrolladas en Francia a principios de la década de 1730 para los cruceros de 60 y 70 cañones,

65. Serrano, 2011: 294-295, 300. VAldez-Bubnov, 2011: 233-268. 
un punto relevante si se tiene en cuenta la importante actividad de Ciprian Autran y otros constructores franceses en los astilleros departamentales tras la muerte de Gaztañeta. Desde una perpectiva tecnológica, esto representa el final del período de transición entre el sistema Habsburgo y el borbónico ${ }^{66}$.

Durante este período también se ensayó la construcción por administración directa total en Coatzacoalcos, Veracruz, donde en I734 se botó al agua el navío de 60 cañones Nueva España, construido bajo la dirección del ya mencionado Juan Pinto. Este astillero fue abandonado en I736, ante la fuerte inversión estatal requerida para mantenerlo operativo. La construcción naval en ese enclave requería no sólo de recursos financieros, sino también de herrajes y otras manufacturas que debían ser transferidos desde el arsenal de La Habana. Esto convertía al proyecto veracruzano en una fuerte diversión de recursos de la principal base naval del Caribe. Aunque algunos empresarios locales presentaron proyectos para vincular la construcción de navíos en aquella zona con otras actividades económicas, la corona optó por la decisión económicamente más racional de centralizar la construcción naval en Cuba. Los astilleros de Realejo y Guayaquil, por su parte, continuaron operando para suplir la navegación de cabotaje en el Pacífico americano, por medio de la participación de las autoridades virreinales y de empresarios activos en la zona ${ }^{67}$.

Durante este período de consolidación del proyecto borbónico en España y América, la construcción naval en Filipinas siguió constituyendo, también, uno de los principales focos de interés estratégico de la corona. El 6 de julio de I7I4 se expidió una Real Cédula ordenando una supervisión estricta de las operaciones de construcción en los astilleros filipinos, la cual era considerada dispendiosa y perjudicial a la Real Hacienda. En el mismo sentido, la ya mencionada transferencia de la Casa de Contratación de Sevilla a Cádiz, en I7I7, señaló el endurecimiento de la posición de la corona ante las prácticas de la construcción naval en el Pacífico. En I7I 8, se reiteró una prohibición contra el tráfico de sedas chinas, extensiva a la seda en rama, y en 1720 el límite del valor total de las mercancías, vigente desde I702, tuvo que ser refrendado. En ese año también se autorizó un ligero incremento del porte máximo de los navíos, fijado en ahora en 560 toneladas. La estrecha conexión entre la legislación mercantil y los reglamentos de construcción naval del Pacífico dio un nuevo giro a partir de 1723 , cuando el gobernador de las islas, marqués de Torre Campo, recibió del presidente del Consejo de Indias, Andrés de Pez, una orden acompañada de una copia manuscrita de las Proporciones de las más essempciales de Gaztañeta, la cual le informaba que esta legislación debía ser obedecida también en los astilleros del Pacífico. Otra carta, firmada por Joseph Rodrigo, señalaba que las especificaciones de Gaztañeta debían emplearse para la construcción de navíos, tanto mercantes como de armada, lo cual es una confirmación más de la continuidad conceptual de los diseños de Gaztañeta con aquellos definidos por las Ordenanzas del período Habsburgo, y demuestra que la distinción tajante entre diseños de guerra y de comercio aún no se efectuaba en este período. El bando de

66. VALDEZ-BUBNOV, 2011: 236, 237, 238, 240, 251

67. Torres SÁNCHEZ, 2016: 153 y ss. 
obedecimiento fue subsecuentemente pregonado en las principales poblaciones de la provincia de Batayán, Mindoro, Pangasinan, Zebú, Yligan y Panai. En I727 se botó en Cavite el Nuestra Señora de Guía, de 500 toneladas, construido bajo estas normas. Esta coincidencia entre la legislación vigente y el tonelaje de los buques producidos en Filipinas representa un hito desde el punto de vista de la obediencia de las élites locales a la política tecnológica dictada por la corona. A partir de I730, el comercio entre Nueva España y las Filipinas estuvo regido por un reglamento experimental, vigente por cinco años, el cual permitía un incremento substancial tanto del valor de la carga como del retorno en plata transportado por las flotas anuales. El porte de los navíos, sin embargo, se estableció en 500 toneladas, y las autoridades filipinas, bajo la gubernatura de Valdés Tamón, construyeron otros dos buques Gaztañeta de esas dimensiones, bautizados Nuestra Señora de Covadonga y Nuestra Señora del Pilar, botados en Cavite en $1733^{68}$. En I734, tras diversas tensiones políticas, el reglamento experimental fue aprobado, con lo cual el porte de los navíos quedó nuevamente fijado de manera oficial en 500 toneladas $^{69}$. En ese mismo año, sin embargo, se imprimió en Manila un importante tratado de construcción naval que detallaba las proporciones de un navío de 70 cañones de casi Iooo toneladas, en dos versiones diferentes: una diseñada específicamente para la guerra, y la otra, para el comercio ${ }^{70}$. En este sentido, la construcción naval española en el Pacífico daba un paso simultáneo y semejante a la del Atlántico, al establecer una clara separación teórica entre diseños mercantiles y militares, distinción que, como hemos señalado, no se encontraba presente en la legislación de Gaztañeta, pese a su título.

En Europa y América, el proceso de centralización de la construcción naval dio un nuevo y trascendental paso con la constitución del Almirantazgo, en I737. Este órgano rector de la Real Armada, bajo la dirección del sucesor de Patiño, Zenón de Somodevilla (marqués de la Ensenada), aprobó en ese año una nueva y más completa Ordenanza para la Matrícula de Mar ${ }^{71}$. Ésta se encontraba basada en el anterior reglamento de $\mathrm{I726}$, el cual se mencionaba explícitamente como antecedente para el registro de toda la gente de mar en un "gremio separado», libre de los sorteos por quintas, del reclutamiento para el Ejército, de la obligación de alojar oficiales, y de determinadas contribuciones concejiles. La nueva Ordenanza estaba dirigida a las poblaciones marítimas en general, incluyéndose, en el primer artículo, una mención específica a la maestranza dedicada a la construcción de buques de guerra. Este es el primer indicador específico de la nueva relación establecida entre la matrícula y los obreros de la construcción naval, los cuales quedaban sujetos a las mismas obligaciones que el resto de la gente de mar. El cuerpo de la Ordenanza, de hecho, está dedicado a detallar los privilegios jursidiccionales y económicos de las poblaciones que decidieran matricularse, aunque el derecho a ejercer las profesiones marítimas, específicamente, el servicio mercante y la pesca con embarcación, quedaba condicionado al registro en la matrícula y, por ende, al servicio en los bajeles de la Real

\footnotetext{
68. García del Valle Gómez, 1993.

69. BARRIO MUÑOZ, 2012: 251.

70. VALDEZ-Bubnov, 2017A.

71. Reproducida en SALAS, 1870: 167-169
} 
Armada o en los astilleros y arsenales del rey. Así, pese a que, aparentemente, se trataba de un paso voluntario, el registro en la Matrícula quedaba convertido en un requisito obligatorio para el ejercicio de todas las profesiones marítimas. Una Instrucción añadida en en ese mismo año impuso un control más estricto sobre los individuos de maestranza, distinguiendo a los carpinteros de ribera y calafates de los carpinteros de blanco, y otros oficios menores. A los primeros se exigía acreditar experiencia en obras del rey para que un quedar matriculados de manera permanente, mientras que los segundos podían contratarse según las necesidades de cada obra específica, pero sin formar parte de la Matrícula. Según Vázquez Lijó, esto habría permitido que un gran número de trabajadores de maestranza se desempeñaran en la construcción naval sin formar parte de los registros, aunque claramente se trataba sólo de los rangos profesionales inferiores a los carpinteros de ribera y los calafates. Como en las ediciones anteriores, este reglamento ofrecía diversos privilegios, como el Fuero de Marina, la exención de Quintas, la liberación de cargas concejiles, y el derecho a ejercer la pesca y navegación. Los límites de edad para el registro en esta nueva versión de la matrícula abarcaban prácticamente toda la vida laboral de un individuo, hasta los 60 años $^{72}$.

Este proceso de intervención estatal sobre las prácticas laborales de la construcción naval tuvo su paralelo en Filipinas. En I736, el gobierno de Manila promulgó una Instrucción para normar la movilización de mano de obra en los cortes de maderas y las operaciones de astillero. Esta medida representó una respuesta administrativa a uno de los principales problemas de la industria: la sobre-explotación de las poblaciones locales por parte de los encomenderos y de los oficiales encargados de la construcción naval ${ }^{73}$. Se trataba de un problema antiguo, pues existen numerosos testimonios, desde principios del siglo XVII, acerca de las dificultades padecidas en estas operaciones ante la escasez o reticencia de la mano de obra local ${ }^{74}$. La Instrucción establecía una clara separación entre la administración gubernamental y los oficiales madereros, al prohibir que los alcaldes mayores continuaran teniendo autoridad, tanto en los cortes como en los trabajos de astillero. Estas responsabilidades eran transferidas a una junta de construcción bajo la dirección de un capítán y un alférez nombrado para el propósito. A su vez, esta junta debía nombrar a los cabos de cortes, los ahiladores y los mandadores de diverso orden. El espíritu de este reglamento era contener los abusos ejercidos consuetudinariamente, no sólo por los oficiales españoles, sino también por las autoridades indígenas encargadas de la movilización de trabajadores para los polos. El principal rubro estaba dedicado a la práctica de la opa, un mecanismo de sustitución por medio del cual un trabajador movilizado para el polo pagaba determinada cantidad en dinero para enviar a otro en su lugar. Los encargados de las colección de las opas eran los Cabezas de Barangay, quienes retenían parte de estas cuotas, o las imponían de manera desmedida. Los cabos, por su parte, eran conocidos por obligar a los trabajadores opados a realizar trabajos

72. VÁZQUEZ Lıó, 2006: 257, 265, 266.

73. AGI, FILIPINAS, 285, N.1.

74. Para una sugerente introducción a este tema: SALES-COLIN, 2013: 68 y ss. 
en su beneficio particular. Más aún, solían apropiarse de parte de los productos obtenidos por medio de los ya mecionados vandalas, además de impedir que los trabajadores llevasen sus propios víveres a los campamentos de corta (reales) y a los astilleros, con el fin de obligarles a comprar en tiendas establecidas ex profeso, y aprovisionadas por medio de los mismos vandalas. El reglamento estandarizaba el monto de las opas, los meses y horarios de trabajo por cada polo, las cantidades pagadas por la Real Hacienda por socorros pagados a cada trabajador, pagados en raciones de arroz, y finalmente las prácticas disciplinarias de reales y astilleros. Un elemento relevante es que la autoridad para vigilar el cumplimiento de estas disposiciones reacaía, de manera oficial, sobre los padres capellanes de la orden religiosa asignada en la provincia en que tuviesen lugar la operaciones. Así, las órdenes religiosas se convertían en un pilar fundamental de los nuevos mecanismos para la movilización de mano de obra para la construcción naval. Efectivamente, los sacerdotes obtenían autoridad para imponer graves penas, tanto a los oficiales españoles como a los cabezas de Barangay, todas especificadas con precisión en el reglamento ${ }^{75}$.

La Instrucción fue complementada en 1738 por una Compulsa concebida para normalizar las operaciones de astillero. Este segundo reglamento estaba basado en criterios de eficiencia en la labra de maderas, así como en el uso de los caudales y los diversos materiales de construcción introducidos en el astillero de Cavite, reduciendo, a un mismo tiempo, el número de trabajadores de maestranza obtenidos de cada provincia por medio del polo. Desde el punto de vista de la movilización de mano de obra, su caracterísitica más relevante era el establecimiento de la obligación de haber servido en el astillero durante un tiempo determinado para acceder al privilegio de sentar plaza como marinero en los galeones. Esto confirma que la posibilidad de participar en el tráfico entre Manila y Acapulco era el principal estímulo para trabajar en la construcción naval, no sólo al nivel de los encomenderos y de los oficiales con autoridad sobre reales y astilleros, sino también al nivel de la maestranza indígena ${ }^{76}$. Así, el ejercicio de los oficios náuticos -en este caso, la marinería de los galeones- quedaba condicionado, tal como en el caso de la Matrícula de Mar, al servicio previo en la construcción naval para el Estado ${ }^{77}$.

El Almirantazgo experimentó también con otras formas de relaciones contractuales para el fomento de la construcción naval. Entre I739 y I748, el Imperio español se vio envuelto en el dos conflictos internacionales: la Guerra del Asiento, también llamada de la Oreja, y la Guerra de Sucesión Austríaca. La presión económica de la guerra tuvo un efecto negativo para la construcción naval en la Península Ibérica. Así, la principal adición de navíos a la Real Armada en Europa provino del embargo de buques pertenecientes a empresarios de la carrera de Indias. Siete unidades fueron obtenidas por este medio $y$, aunque sus dueños quedaron disconformes con las compensaciones ofrecidas por la Real Hacienda después de varios años de

75. AGI, FILIPINAS, 136, N. 1. Los alcances de esta medida, así como su distribución territorial, son actualmente objeto de un nuevo estudio por parte del autor.

76. AGI, FILIPINAS, 149, N. 1 .

77. VALDEZ-BUBNOV, 2017B: 257-258. 
litigio, los buques sirvieron brillantemente en la campaña mediterránea de I744, combatiendo con eficacia en la que sería conocida como Batalla de Cabo Sicié. La paralización total de la industria de la construcción naval en Europa fue compensada con creces por la productividad de los astilleros americanos y asiáticos. En ese año se formó una compañía por acciones para la explotación de la hoja de tabaco en la isla de $\mathrm{Cuba}^{78}$. A cambio de este y otros privilegios, la compañía se comprometió a construir diez navíos en el astillero de la Tenaza, en la bahía de La Habana. Esto representó una solución a diversos problemas técnicos generados por la concentración de responsabilidades empresariales, técnicas y administrativas en la persona de Juan de Acosta. La posición de Acosta como Capitán de Maestranza se mantuvo intacta, mientras que la dirección técnica de las obras estuvo en manos de otros oficiales ministeriales, especialmente de Lorenzo de Montalvo y Rodrigo de Torres. Como parte de los esfuerzos por controlar a Acosta y a sus redes empresariales, Montalvo solicitó, en I747, la implantación de la Matrícula de Mar en Indias. Esta petición fue cancelada antes de su puesta en práctica, debido a la oposición del gobernador de la isla de Cuba, Francisco Cagigal ${ }^{79}$. En el caso de Filipinas, la guerra también tuvo importantes efectos en la industria de la construcción naval. En I743, uno de los navíos Gaztañeta de 500 toneladas contruidos por Valdés Tamón, el Nuestra Señora de Covadonga, fue capturado por el británico Centurion. El suceso generó una gran conmoción etre los grupos mercantiles de México y Manila, y fue ampliamente explotado por la propaganda inglesa. Así, resulta significativo que las siguientes operaciones de construcción naval en la bahía de Manila, comisionadas durante la gubernatura interina del Obispo de llocos, produjesen un navío que superaba en más de tres veces el porte de sus predecesores: el Nuestra Señora del Rosario y los Santos Reyes, de I7io toneladas, botado al agua en $1745^{80}$.

El fin de la guerra, en $\mathrm{I748}$, coincidió con la extinción del Almirantazgo, y señaló el ascenso del marqués de la Ensenada a la Secretaría de Marina. Con esto dio inicio de una de las etapas más productivas del sistema de construcción naval del Imperio español. El nuevo monarca, Fernando VI, coronado tras la muerte de Felipe V en I746, hizo suya la estrategia ensenadista de buscar una posición independeniente en la arena internacional. La espina dorsal de este proyecto era una vigorosa política de rearmamento naval que le permitiese actuar como árbitro de la paz y la guerra entre los dos principales potencias europeas -Francia e Inglaterra- sin alinearse totalmente con ninguna. En ese mismo año, una concentración de contratos en el asentista privilegiado Juan de Ysla (también comisario ordenador de Marina), hizo posible la ejecución de un vasto programa de cortes madereros en La Montaña, Santander. El propósito era iniciar un ambicioso programa de construcción de 44 navíos Autrán de 70 cañones, bajo las condiciones previstas originalmente por Patiño, es decir, en grandes series estandarizadas, producidas por administración directa en los arsenales departamentales $^{81}$. Sin embargo, Ysla pronto recibió una nueva comisión por parte

78. Serrano, 2013: 111 y ss.

79. Martínez Shaw y Alfonso Mola, 2005: 273.

80. MARLEY, 1991

81. MAISO, 1990. 
de Ensenada: reactivar el astillero tradicional de Guarnizo, y construir una nueva serie de cuatro navíos (luego extendida a ocho), bajo la condición explícita de reducir sus costos en relación con la producción de los arsenales departamentales. Esto coincidió con la importación de un gran número de técnicos británicos a España, tres de los cuales pasaron a dirigir las operaciones de construcción por administración directa en Cádiz, Cartagena, Ferrol y, posteriormente, también las correspondientes a la contrata de Ysla en Guarnizo. Mientras tanto, en Cuba, los últimos buques correspondientes a la serie originalmente contratada con la Real Compañía de La Habana eran botados al agua. En Filipinas, por otra parte, el nuevo gobernador, marqués de Ovando, comisionó la construcción de un nuevo buque en el Real Astillero de Bagatao, bajo la dirección de Domingo de Nebra. Se trataba del Santísima Trinidad y Nuestra Señora del Buen Fin (alias El Poderoso), de 2000 toneladas. Claramente, los buques del Pacífico habían superado con mucho las dimensiones de sus contrapartes del Atlántico, alcanzando de nuevo los enormes tonelajes de la primera mitad del siglo XVII ${ }^{82}$.

En I75I, la normatividad de la Matrícula de Mar fue incorporada a las Ordenanzas Generales de la Armada ${ }^{83}$, recogiendo todos los puntos fundamentales de los reglamentos expedidos por el Almirantazgo en I737, con algunas importantes diferencias para las profesiones de la construcción naval. Los carpinteros de ribera y los calafates sólo podían ejercer tras haber servido durante dos campañas en los bajeles de la Real Armada, a partir de lo cual gozarían de los privilegios compensatorios de la Matrícula. En contraste, los oficios menores de la construcción naval (listados como carpinteros de blanco, toneleros, aserradores, armeros, torneros, herreros, pintores, faroleros y fabricantes de jarcia, lona y betunes) no quedaban obligados a registrarse en la Matrícula, pero solamente disfrutarían de sus privilegios durante las obras para las que hubiesen sido contratados. Para todas las profesiones náuticas, el registro en la Matrícula quedaba convertido en requisito obligatorio para ejercer la pesca en embarcaciones y la marinería. Una vez expedido este reglamento, tuvo lugar un segundo intento por implantar de manera local la legislación de Matrículas en América. Efectivamente, en I757, el gobernador de Cartagena de Indias solicitó su implantación en ese puerto, pero, tal como en el intento realizado diez años antes por Montalvo en La Habana, este empeño fue rechazado por la Secretaría de Marina, ante los potencialmente perniciosos efectos sociales de condicionar las prácticas consuetudinarias de la navegación y la pesca al servicio en los bajeles y astilleros del rey ${ }^{84}$. Las poblaciones marítimas de las provincias de Vizcaya y Guipúzcoa, así como posteriormente Castro Urdiales y Canarias, no fueron incorporadas al regimiento de Matrículas ${ }^{85}$. Esas provincias continuaría rigiéndose por las ordenanzas de sus gremios locales, así como por las autoridades de los concejos villanos, siempre y cuando ejercieran dentro de sus límites geográficos. Al emplearse en otras regiones del Imperio, así

\footnotetext{
82. MARLEY, 1993

83. ORDENANZA, 1751

84. Martínez Shaw y Alfonso Mola, 2005: 273, 274

85. Serna Vallejo, 2016: 48 y Ss.
} 
como en los astilleros y arsenales del rey, debían quedar sujetos a los reglamentos de matrículas.

A partir de 1754 se registró un importante cambio en la política exterior de Fernando Vl, el cual tuvo profundos efectos en la política de construcción naval de los siguientes diez años. Ensenada fue apartado de sus carteras ministeriales, debido a que su política naval fue presentada al monarca como una toma de posición anti-británica, contraria al espíritu de paz armada que animaba su estrategia diplomática. Su sucesor al frente de la Secretaría de Marina, Frey Julían de Arriaga, no sólo se encontró privado del control directo sobre las finanzas navales del cual habían gozado sus predecesores, sino que también tuvo que enfrentar progresivos recortes en las consignaciones anuales ${ }^{86}$. Como resultado, al concluirse los programas de construcción por administración directa en los arsenales departamentales, no se proyectaron otros nuevos, mientras que Juan de Ysla, el principal agente de la iniciativa privada en la construcción naval, fue privado de su contrato en Guarnizo y encarcelado. Los dos últimos navíos de su serie fueron terminados por Juan Bauptista Donesteve, un contratista anteriormente asociado con él. Por otra parte, la práctica de otorgar contratas de construcción naval a operarios de maestranza, previamente ensayada en La Habana, cobró un nuevo ímpetu en I758, con la botadura del navío El Campeón, en el arsenal de Cartagena. Se trata de un punto revelador, pues el contrato para la construcción de este buque especificaba que la única responsabilidad de sus cuatro empresarios -todos contramaestres de construcción del arsenal- era el reclutamiento, administración y pago de la mano de obra en el astillero. Esto señala una clara diferencia con las relaciones contractuales de períodos anteriores en la industria de la construcción naval, y las detalladas relaciones del proceso sentaron un nuevo precedente laboral y empresarial en los arsenales estatales ${ }^{87}$.

En este mismo período, Fernando VI, tal como lo había hecho anteriormente Felipe V, intentó tomar medidas ante los efectos económicos del enorme crecimiento de los navíos de la carrera del Pacífico. El 29 de abril de 1756 , el rey ordenó la sustitución del Santísima Trinidad, en principio, debido a sus malas características de navegación, pero también debido que su enorme capacidad de carga era percibida como un mecanismo para introducir mercancías en Nueva España, muy por encima de las autorizadas por la legislación mercantil. Para este propósito, se enviaron recursos financieros desde Acapulco, para la construcción de dos fragatas. Sin embargo, las autoridades filipinas, en lugar de iniciar la construcción de estos dos buques, utilizaron los recursos para modificar al Santísima Trinidad, buscando oficialmente mejorar sus cualidades marineras, pero sin alterar substancialmente su capacidad de carga. En I757 se eliminó completamente su cubierta superior, sustituyéndola por un castillo con dos portas de artillería y un alcázar con seis. ${ }^{88}$ Se trata, nuevamente, de un caso de desobediencia a las políticas

86. BAUDOT MONROY, 2012B: capítulo XII; 2017: 195-224.

87. VALDEZ-BUBNOV, 2018: 114-115.

88. MARLEY, 1993: 176-177. 
tecnológicas dictadas por la corona, motivada por los intereses de los comercianes de la ruta Manila-Acapulco.

\section{LA SEGUNDA FASE DEL LARGO SIGLO XVIII: LA POLIITICA DE CONSTRUCCIÓN NAVAL DURANTE LOS REINADOS DE CARLOS III, CARLOS IV Y FERNANDO VII (1763-1834)}

El desenlace de la Guerra de los Siete Años (1756-63) generó un cambio importante en el balance de poder entre las tres principales potencias navales europeas. Este cambio tuvo efectos tan trascendentales en las industrias de construcción naval que justifica considerar a este como un segundo ciclo evolutivo, el cual, en términos administrativos y tecnológicos, mantuvo características estructurales relativamente homogéneas hasta la fragmentación del Imperio durante el primer tercio del siglo XIX. El gobierno de Carlos III siguió una política exterior eminentemente navalista, basada en una estrecha alianza con Francia y dirigida en contra de Gran Bretaña. La naturaleza esencialmente ofensiva de la alianza borbónica se tradujo en una planta de armada basada en un poderoso núcleo de navíos de línea de tres puentes, concebidos para disputar el dominio del mar en encuentos decisivos, apoyado por una proporción substancial de nuevos cruceros de dos puentes, fuertemente artillados, así como por diversos rangos de unidades menores para el servicio a la descubierta. Estos parámetros doctrinales y tecnológicos definieron la producción tanto en España como en América, y se mantuvieron a lo largo de los reinados de Carlos IV (I788-I808) y de Fernando VII (I808 y I8I4-33). Desde una perspectiva administrativa, en cambio, las reformas más importantes de este período representan una intensificación de las medidas de control empresarial y de mano de obra iniciadas durante el período anterior, con la importante diferencia de que la infraestructura material de la corona se encontraba ya plenamente operativa. Esto hizo posible niveles crecientes de control estatal sobre los procesos productivos, llevados a cabo a través de nuevas formas de reglamentación tanto de las contratas como de la maestranza, gradualmente transferidas a todo el Imperio, aunque con variantes regionales. En el caso del Pacífico, a lo largo de este período tuvieron lugar transformaciones profundas en la estructura mercantil de la Carrera de Filipinas, las cuales, a su vez, afectaron directamente la industria de la construcción naval ${ }^{89}$. En efecto, las reformas al comercio dieron lugar a una cada vez mayor presencia de la Real Armada en las islas, hasta que, ya en el siglo XIX, la legislación de construcción naval en Filipinas fue homologada, en términos relativos, con aquella vigente en España y América.

89. Estos cambios han sido hasta ahora escasamente tratados por la historiografía. Su interpretación más detallada y completa se encuentra en la contribución de María Baudot Monroy, en este mismo número monográfico, por lo que remitimos al lector a ella. 
La política naval conjunta desarrollada por las potencias borbónicas a partir de I763 señaló el inicio de importantes reformas en los sistemas navales de las coronas francesa y española. En el caso español, la primera medida fue reactivar la construcción naval en los arsenales departamentales y, posteriormente, también en Guarnizo. Esto se llevó a cabo, no por medio de la administración directa, sino por nuevas contratas con empresarios italianos en el arsenal de Cartagena (Monticelli, Marcenaro, Agnesse, Ratti), y con empresarios cantábricos en el astillero de Guarnizo (Juan Bauptista Urquidizaz, Manuel de Zubiria y Juan Bauptista Donesteve). Las grandes series de navíos construidas por administración directa durante la secretaría del Marqués de la Ensenada habían llegado a su fin en el contexto de una marcada reducción presupuestal, impulsada por el giro pro-británico en la diplomacia de Fernando Vl. Así, la reactivación de la construcción naval durante los primeros años del gobierno de Carlos IIl se basó en la capacidad empresarial expresada en la firma de aquellas contratas. Sin embargo, el margen de acción de los asentistas de la construcción naval se vio muy pronto reducido por la colaboración adminstrativa entre las dos coronas borbónicas. A partir de I767, diversos técnicos franceses -bajo la dirección de Jean Maritz- comenzaron a intervenir las fábricas de artillería, en Sevilla y Santander, importando nuevos sistemas para la producción de cañones navales. Por otro lado, un ingeniero naval de la misma nacionalidad -Francois Gautier- comenzó a dirigir, inicialmente como constructor de navíos, las series contratadas con Zubiria en Guarnizo.

Esto coincidió con nuevas medidas administrativas para intensificar la militarización de la maestranza: en i768 se enfatizó la obligación explícita de acreditar servicio en la construcción de buques de guerra para poder ejercer las profesiones de la construcción naval, incluso para empresarios particulares ${ }^{90}$. Por otra parte, la dirección técnica de las operaciones de construcción naval dio un nuevo e importante paso en I770, con la creación del Cuerpo de Ingenieros de Marina, bajo la dirección de Gautier ${ }^{91}$. El Reglamento de esta nueva corporación, promulgado en I $772^{92}$. estableció una serie de lineamientos para normar las operaciones construcción naval por administración y por contrata. Con esto, tanto la maestranza como los asentistas quedaban enteramente supeditados a la autoridad de los ingenieros, quienes debían establecer las cláusulas del contrato, las condiciones laborales, las etapas y calendarios de operación, y además quedaban a cargo de la disciplina en arsenales y astilleros. La actividad de los empresarios, en cambio, quedaba reducida a reclutar y supervisar la mano de obra en las operaciones previamente definidas por los ingenieros ${ }^{93}$. Estas disposiciones fueron reafirmadas en un nuevo reglamento para la administración de la infraestructura de los departamentos: la Ordenanza de Arsenales de $1776^{94}$. Esta doble vertiente legislativa, dedicada a la militarización de la mano de obra, por un lado, y la subordinación de los asentistas al Cuerpo de

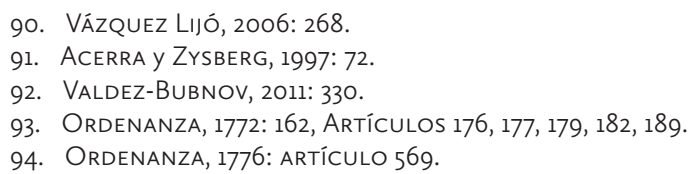


Ingenieros, por otro, obliga a una reflexión acerca de la evolución de la construcción naval por medio de contratas con la iniciativa privada. La construcción por asiento en los astilleros tradicionales de la Península Ibérica fue la fuente más importante de navíos para la Real Armada durante la primera mitad del siglo XVIII, seguida tan sólo por las compras en el extranjero, y con la construcción por administración estatal directa en los arsenales departamentales y en América en un distante segundo lugar. Sin embargo, las condiciones para los contratos de construcción naval con empresarios particulares fueron progresivamente centralizadas, hasta el punto de convertir a la maestranza en una corporación estrictamente sujeta a disciplina militar, incluso condicionando su práctica en la industria civil al servicio previo en los astilleros y arsenales del rey. De manera convergente, la reglamentación de Ingenieros y de Arsenales limitó el papel de los contratistas a meros administradores de mano de obra, transfiriendo las funciones técnicas y logísticas el Cuerpo de Ingenieros. Esto representa un cambio significativo en relación con los contratos de construcción naval del período Habsburgo tardío y borbónico temprano, los cuales otorgaban al empresario la facultad de movilizar y administrar, bajo sus propios criterios de eficiencia, una mano de obra que, a su vez, se contrataba de manera independiente, o bajo las normas de sus respectivas cofradías. Una vez que el nuevo modelo estuvo operativo, la Secretaría de Marina comenzó a estimular a los trabajadores de maestranza para formar sociedades dedicadas a tomar bajo contrato las operaciones de construcción de navíos específicos. En este nuevo tipo de contrato, las responsabilidades del asentista se limitaban a la movilización de maestranza matriculada. Esta es, precisamente, la naturaleza del contrato de construcción naval del siglo XVIII tardío.

En La Habana, los años inmediatamente posteriores a la Guerra de los Siete Años presenciaron un decidido esfuerzo por desarrollar la construcción por administración directa. El punto de partida fue una orden, expedida en I764, para iniciar un programa de la construcción de cuatro navíos - dos de 64 y dos de 70 cañonesfinanciado a partir de un incremento en los situados de plata recibidos de Nueva España. Esto, sin embargo, presentó dificultades, pues el situado era distribuido entre diversas áreas de la administración, no sólo de la isla de Cuba, sino también de otros enclaves navales del Caribe. Como resultado, el intendente Lorenzo de Montalvo inició la práctica de recaudar préstamos con interés entre la élite local para financiar las operaciones de construcción naval por cuenta de los situados venideros. Esta práctica fue decisiva para el mantenimiento del esfuerzo naval español en La Habana durante las siguientes tres décadas y, ciertamente, permitió hacer cálculos optimistas sobre la productividad del astillero: en I767, Montalvo recibió la orden de incrementar la producción a cuatro nuevos buques cada año ${ }^{95}$.

Las medidas llevadas a cabo en Cuba durante los últimos años de la década de I76o fueron tan sólo uno de los aspectos del esfuerzo de construcción naval español en América. Desde 1766, se había estudiado la posibilidad de desarrollar la construcción naval en el occidente de Nueva España. Así, se transfirió a un constructor 
naval anteriormente establecido en Veracruz -Alonso Francisco Pacheco- quien estableció un astillero en la bocana del Río Santiago. Este fue el primer paso para el establecimiento del nuevo Departamento Marítimo de San Blas, posteriormente denominado Apostadero, con financiación directa de las rentas reales de las salinas y el tabaco de Nueva España ${ }^{96}$. El astillero fue dotado de su propia maestranza, y durante las siguientes dos décadas botó al agua varias unidades menores bajo la dirección de constructores provenientes de Guarnizo y Ferrol. Sin embargo, según ha señalado Pinzón Ríos, la escasez de operarios hizo que se contratara individuos de manera indistinta y frecuentemente temporal, bajo la promesa de inclusión en la Matrícula de Mar $^{97}$. Durante este período también se estudió la posiblidad de establecer astilleros permanentes en Coatzacoalcos y Guayaquil. Sin embargo, los altos costos de la transferencia de productos manufacturados hasta esos enclaves condujeron al abandono de ambos proyectos, así como de otros dedicados a los puertos de Realejo, en Centroamérica y de San Carlos de Chiloé, en el Pacífico sur ${ }^{98}$.

En I776, la Matrícula de Mar fue finalmente implantada en América, con base en la legislación incorporada a las ordenazas de Armada desde i75I. Sin embargo, tal como ocurrió anteriormente, la medida generó oposición por parte de las autoridades locales, debido a los posibles conflictos sociales derivados de condicionar las prácticas de la navegación y la pesca al registro en la matrícula. Es importante señalar que estas prácticas habían sido declaradas libres por las Leyes de Indias, lo cual representaba un formidable obstáculo para la implantación de la jursidicción naval. Esta vez la impugnación de la matrícula no fue respaldada por la corona, pero, en I783, se permitió la cancelación de las restricciones sobre la navegación y la pesca. Así, desde I780, la Matrícula de Mar quedó formalmente establecida en los dos principales astilleros de Nueva España: Veracruz y San Blas, con las peculiaridades señaladas ${ }^{99}$.

Durante este período se registraron también importantes cambios en la estructura del comercio transpacífico, los cuales afectaron temporalmente la industria de construcción de galeones en los alrededores de Manila. A partir de I765, la corona impulsó una nueva estrategia mercantil para terminar con los inveterados privilegios de la Carrera de Filipinas, por medio de viajes efectuados a través del Cabo de Buena Esperanza, ejecutados por buques pertecientes de la Real Armada en favor del comercio de Cádiz. Esto señaló el inicio de un período de intervención en la construcción naval filipina por parte de la oficialidad de estos buques. En I77I, el nuevo gobernador de Filipinas, Simón Anda y Salazar, organizó una fuerza de navíos menores para el ejercicio del corso regional desde la isla de Corregidor. Esta fuerza fue denominada Marina Sutil, y su construcción y mantenimiento fue delegada en oficiales de la Real Hacienda ${ }^{\text {Io }}$. Su existencia estuvo siempre ligada a los beneficios económicos de la guerra de corso, principalmente contra los moros de Mindanao,

96. ThurmanN, 1967: 54, 65, 96, 97.

97. Pinzón Ríos, 2011: 90, 91, 92, 93, 94, 95, 96.

98. VALDEZ-BubNOV, 2011: 378, 379, 387, 399 .

99. Martínez Shaw y Alfonso Mola, 2005: 205, 277, 284.

100. Franco Castañón, 2012: 49. 
y que su oficialidad resistió administrativamente la creciente intervención de los oficiales de la Real Armada en la construcción naval.

Entre 1778 y I783, Francia y el Imperio español intervinieron en la Guerra de Independencia de los Estados Unidos. La superioridad númerica y tecnológica de ambas marinas, así como el apoyo político, militar y financiero a los rebeldes, resultaron decisivos para la desintegración del Imperio británico en Norteamérica. En el caso específicamente español, las actividades de construcción naval se reactivaron a partir de $\mathrm{I7} 83$, nuevamente con un fuerte caractér centralizado y militar. En ese año, el discípulo y sucesor de Gautier en la dirección del Cuerpo de Ingenieros, Joseph Romero Fernández de Landa, promulgó un nuevo reglamento para la disciplina en arsenales y astilleros, la cual limitaba explícitamente el papel de los contratistas a la movilización y administración de la mano de obra ${ }^{\mathrm{IoI}}$. De igual forma, imponía nuevos y más estrictos parámetros disciplinarios para la maestranza. En I785, por otra parte, se ordenó que los oficiales del Cuerpo General quedasen a cargo de pasar las listas de matriculados ${ }^{102}$. Al año siguiente, en I786, la Secretaría de Marina promulgó un nuevo reglamento definiendo y ampliando la normatividad de los trabajadores de la construcción naval. Los matriculados quedaban ahora sujetos al pago de cuotas para la conformación de un fondo colectivo, del cual se extraían premios pagados por cada quilla puesta, así como el financiamiento de escuelas, servicios religiosos, funerales, y socorros para emergencias individuales de los miembros de la corporación ${ }^{103}$.

La constitución de la maestranza como gremio con capacidad de autofinanciamiento es un elemento importante para comprender la evolución de la construcción naval por contratas a partir del último tercio del siglo XVIII. La constitución del fondo común normalizaba la práctica de que los miembros de la maestranza tomasen bajo su cargo los contratos de construcción naval, bajo las condiciones ya señaladas. Más aún, en I793 se volvieron a expedir reglamentos específicamente dedicados a carpinteros de ribera y calafates, confirmando los privilegios y restricciones de las ordenanzas anteriores. La principal añadidura fue la prohibición explícita de que los miembros de estas dos profesiones pudieran participar en la pesca, la navegación, o cualquier industria privada sin estar alistados en la matrícula. En el caso de que debieran ejercer estas funciones cuando sirviesen como marineros en los bajeles de la armada, recibirían un medio jornal extra, definido por el ingeniero comandante. También se definía su vida profesional entre los i8 y 45 años, y sólo los jóvenes que no hubiesen alcanzado esa primera edad podían ejercer estas dos actividades en sus pueblos de origen sin estar matriculados ${ }^{104}$.

Así, la admininstración de la construcción naval española quedó sujeta a un proceso de reforma constituido en tres vertienes. La primera fue la concentración de las responsabilidades técnicas en una nueva corporación de carácter militar (el Cuerpo de Ingenieros); la segunda, la constitución de los trabajadores en un

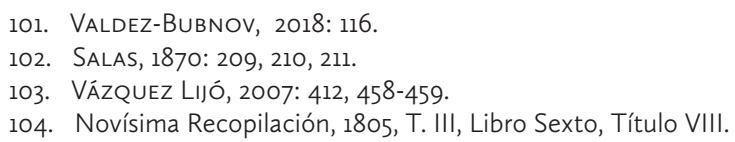


gremio militarizado con relativa capacidad de autofinanciamiento (la maestranza matriculada); y la tercera, la reglamentación de la participación empresarial como una función de las dos anteriores. A partir de este período, la única diferencia entre la construcción naval por administración directa y por contrata empresarial era sobre quién recaía la responsabilidad de movilizar y administrar a los trabajadores: sobre el Estado, o sobre una iniciativa privada, modesta en comparación con los grandes empresarios de otros períodos ${ }^{\mathrm{IO}} \mathrm{y}$, además, de carácter corporativo y militar. Todo ello dista mucho de la naturaleza de los contratos de construcción naval de carácter «total» del período Habsburgo tardío y borbónico temprano. Estas transformaciones no representaban, necesariamente, una reducción de la participación empresarial en esta industria, sino la culminación de una cada vez más sofisticada y estricta división de funciones entre el Estado y las élites empresariales, tanto en España como en América. En efecto: siguió existiendo un amplio margen para la participación privada en diversas industrias subsidiarias del sistema naval, sin que esto necesariamente implicase involucramiento directo en las prácticas de ensamblado de buques de guerra a través del control de los principales procesos productivos. Esto aparece claramente reflejado, por ejemplo, en las contratas para la provisión de víveres y maderas en los arsenales departamentales, firmadas en I788 por el consorcio empresarial conocido como los Cinco Gremios Mayores, así como en la presencia constante y generalizada de diversas contratas menores para la provision de bienes específicos ${ }^{106}$. En Cuba, la élite habanera se hallaba también fuertemente involucrada en las operaciones de astillero, si no ya en los principales aspectos del ensamblado de los navíos, sí como prestamistas a cuenta de las remesas de plata provenientes de Nueva España ${ }^{107}$. Este mecanismo crediticio resultó altamente eficaz, permitiendo la conclusión existosa de las series de navíos proyectadas por el Ingeniero General, Fernández Romero de Landa, entre I784 y I794, de los cuales siete fueron construidos en el astillero cubano.

La generalización de la adminstración directa en la construcción naval fue una política consistente por parte de la Secretaría de Marina. Ésta alcanzó su punto culminante en I792, cuando, tras detallados estudios de costos, se decretó la cancelación de la construcción naval por contrata. A partir de este punto, la administración directa debía ser el único método utilizado en la producción de buques de guerra, aunque los mencionados estudios habían demostrado las relativas ventajas económicas de las contratas. En I796, la centralización del sistema industrial de la Real Armada dio un nuevo e importante paso con la cancelación total de la construcción naval en La Habana. A partir de ese año, una nueva división del trabajo entre España y América situó a Cuba únicamente como productor de maderas, eliminando los costos de la transferencia de herrajes y otros productos manufacturados desde los arsenales departamentales, principalmente de Ferrol. A partir

105. Esta transición hacia contratistas de menor porte, paralela a la política de transferir los contratos de construcción naval a la maestranza matriculada aparece confirmada en: SERRANO, 2013: 121.

106. Torres SÁNCHEZ, 2016: 18, 23, 29, 33, 35, 37, 73, 89, 91, 95, 96, 97, 100, 103, 221.

107. SerRANO, 2013: 122, 123 . 
de entonces, la construcción naval tendría lugar exclusivamente en los arsenales departamentales de la Península Ibérica ${ }^{\mathrm{r} 08}$.

En I799 se expidió un nuevo reglamento señalando que toda obra de construcción realizada por empresarios al interior de la infraestructura perteneciente a la Armada (edificios, gradas, fortificaciones, etc) debía ser contratada exclusivamente con individuos pertenecientes a la maestranza matriculada. Se especificaba que, si para entonces se hallaba vigente algún contrato firmado con empresarios que no pertenecieran a esa estructura gremial, entonces éste debía ser cancelado de inmediato ${ }^{\mathrm{I0} 9}$. Esto representa una confirmación definitva de que los argumentos presentados en el presente estudio -la reducción de la construcción por contrata a la administración de mano de obra, y la consiguiente constitución de la maestranza como única corporación facultada para recibir contratas- no fueron prácticas improvisadas ni privativas de la construcción naval, sino una política industrial congruente y progresivamente definida durante la segunda mitad del siglo XVIII. En I802, la militarización de la maestranza dio un último y contundente paso, con un nuevo reglamento que la colocaba directamente bajo la autoridad de los oficiales del Cuerpo Generaliro.

En Filipinas, la presencia de la Real Armada, entre 1796 y 1803 , tuvo un importante aunque temporal impacto en las prácticas de la construcción naval. La llegada de la denominada Escuadra de Asia, bajo el mando de Ignacio María de Álava, tuvo como medida paralela la transferencia de la maestranza matriculada de San Blas a Cavite ${ }^{\mathrm{III}}$. En 23 de abril de ese año se decretó el establecimiento de la Matrícula de Mar en Filipinas, bajo un reglamento redactado por el gobernador, Rafael María de Aguilar. Este reglamento estableció una división territorial en cinco provincias y, tal como las versiones americanas de la Matrícula, canceló las cláusulas de exclusividad sobre la pesca y la navegación ${ }^{112}$. Es importante señalar que Álava poseía instrucciones de intervenir la construcción naval filipina, y en I797 arribaron a Cavite varios contramaestres de construcción procedentes de La Habana, bajo el mando de Juan Villar. Estos operarios intentaron intervenir un pequeño astillero dedicado a la producción de unidades menores para la Marina Sutil (La Barraca, a orillas del río Pasig), pero se encontraron con resistencia por parte de las autoridades locales, entre ellos el mismo Aguilar. En I8oo, el astillero de Cavite fue reorganizado, empleando a los oficiales y operarios de la escuadra de Álava. Estos cambios resultaron efímeros: el personal de la Escuadra de Asia abandonó Filipinas al finalizar las hostilidades con Gran Bretaña, en I803, con lo cual, la independencia relativa de la construcción naval filipina volvió a convertirse en la realidad de los astilleros locales.

Con el despuntar del siglo XIX, una seria crisis de producción comenzó a perfilarse en el sistema de construcción naval del Imperio, debido a la falta de recursos generada por los efectos combinados de las Guerras Napoleónicas y las

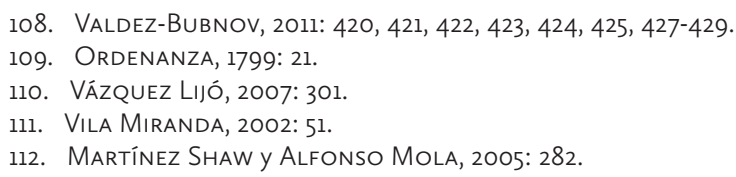


Guerras de Independencia de la América española. Entre I798 y I808 solamente fueron botadas dos nuevas fragatas en los arsenales departamentales. En La Habana se botaron dos fragatas más, en I8o8 y en I8I2, y en Cavite, Filipinas, se construyó una corbeta y varios bergantines entre I8I2 y I8I4. Esta paralización relativa coincide con la extinción de la Matrícula de Mar, promulgada el 3 de abril de i8I2. Este vuelco en la legislación, sin embargo, fue un gesto eminentemente político, y no tuvo efecto en el Imperio, ante el estado de guerra en América, y la distancia de Filipinas. En I8I3, la gubernatura de aquellas islas fue asignada al brigadier José de Gardoqui Jarabeitía, quien, en ese mismo año, decretó la extinción de la Marina Sutil, transfieriendo sus funciones a la Real Armada ${ }^{\mathrm{II}}$. En I8I6, Gardoqui promulgó un reglamento que homologaba la administración de la construcción naval en Cavite con la normativa de la Ordenanza de Arsenales, vigente desde $1776^{\mathrm{II} 4}$.

En I8I7, ante la urgencia representada por los movimientos independentistas en América, se volvió temporalmente a la práctica de comprar buques en el extranjero: siete navíos fueron adquiridos en Rusia, y también se contrató la construcción de otras unidades menores en astilleros franceses. Esto no significa que el gobierno de Fernando VIl, en funciones desde I8I4, hubiese abandonado la política de construcción de su predecesor, Carlos IV, sino que las dificultades financieras y logísticas impuestas por este ciclo de guerra hicieron que las compras fuesen, como lo fueron en otros períodos, una manera expedita de resolver las dificultades en la producción. En ese mismo año de I8I7, un proyecto para definir la nueva planta de Armada especificaba la necesidad de construir navíos de línea de tres y dos puentes, así como diversos tipos de unidades menores ${ }^{\text {II }}$. El rasgo más importante de este proyecto, desde el punto de vista de la política industrial, radica en la especificación de que solamente las unidades menores a las corbetas podían ser construidas por contrata, mientras que todos los demás tipos, hasta los navíos de tres puentes, debían ser construidos exclusivamente por administración directa ${ }^{\mathrm{I} 16}$. Es altamente signifcativo que este proyecto fuese precedido por la apertura de un expediente para reestablecer a Matrícula de Mar, fechado en 20 de febrero de I8I7. La inestabilidad política del Trienio Liberal, sin embargo, condujo a una segunda revocación de la matrícula, promulgada en 28 de octubre de 1820 , aunque fue nuevamente restablecida en $\mathrm{I} 82 \mathrm{I}^{\mathrm{II}}$. En I 825 se redujeron drásticamente los números de la maestranza matriculada en los arsenales departamentales de Cádiz, Ferrol y Cartagena y, además, se decretó que su contratación sería «eventual», es decir, no permanente, y dictada por las obras ${ }^{\text {II8 }}$. La planta de Armada proyectada en I8I7, basada en el restablecimiento de la Matrícula, constituyó precisamente la base del

113. Franco Castañón, 2012: 53: 54-55.

114. Superior Decreto, 1816: Títulos 1-21.

115. EXPOSICIÓN A LAS CORTES, 88, 89

116. Se ha señalado que existe una orden de 1825 para el retorno a la construcción naval por asiento, pero el fundamento de esta afirmación es dudoso, y no es congruente con las disposiciones anteriores y posteriores en este sentido. Sobre esta aparente confusión y una primera afirmación de este argumento: CASTILLO MANRUBIA, 1992: 106-107. Roda Alcantud, 2015: 324. ValdeZ-Bubnov, 2018: 121

117. Martínez Shaw y Alfonso Mola, 2005: 282.

118. RODA ALCANTUD, 2015: 324. 
proyecto para la reactivación de la construcción naval presentado a las Cortes por el ministro de Marina Joseph Vázquez de Figueroa en I834. Siginficativamente, este nuevo y último programa de construcción naval reafirmaba que los contratistas, necesariamente, tenían que formar parte de la maestranza matriculada, confirmando la exclusividad del gremio en este rubro, así como la continuidad y la congruencia de la política contractual desarrollada, no sólo a partir de la Guerra de los Siete Años, sino desde los tiempos de Patiño. En ese mismo año, I834, se botó al agua en Cavite el último buque producido dentro de los parámetros del largo siglo XVIII del Imperio español: la fragata Esperanza. 


\section{FUENTES IMPRESAS}

Exposición a las Cortes, Madrid, Imprenta Real, I834.

Novísima recopilación, Tomo III, Libro VII, Título VII, Madrid, I805.

Ordenanza para el régimen y fomento de la marinería matriculada. Título III del Tratado X de las Ordenanzas Generales de la Real Armada, Madrid, I75I.

Ordenanzas de Marina para los navíos del Rey de las Islas Philipinas, Sin lugar, sin imprenta, I757.

Ordenanza de SM para el servicio del Cuerpo de Ingenieros de Marina, Madrid, Pedro Marín, I772.

Ordenanza de SM para el gobierno de sus Reales Arsenales de Marina, Madrid, Pedro Marín, I776.

Ordenanza de SM para el gobierno económico de la Real Hacienda de Marina, Madrid, Pedro Julián de Pereyra, I799.

Superior Decreto, Filipinas, Superior Gobierno, i8ı6.

\section{BIBLIOGRAFÍA}

Acerra, M. y Zysberg, A., L'essor des marines de guerre européenes (I680-I790), Paris, SEDES, I997.

AlONSO, L., «Los señores del Barangay. La principalía indígena en las islas Filipinas, I565I789: viejas evidencias y nuevas hipótesis», en M. Bornemann, y R. Aguirre, El cacicazgo en Nueva España y Filipinas, México, UNAM, 2005: 355-406.

Alonso, L., El costo del Imperio asiático. La formación colonial de las islas Filipinas bajo dominio español, I565-I800, México, Instituto Mora-Universidad de la Coruña, 2009.

BARrio Muñoz, J. A., Vientos de reofrma ilustrada en Filipinas. El gobernador Fernando Valdés Tamón (I729-I739), Sevilla, CSIC, 2012.

Baudot Monroy, M., «Barcos para el rey: Julián de Arriaga, la madera y la construcción naval, I572-I759» en M. R. García Hurtado (ed.), La armada española en el siglo XVIII: ciencia, hombres y barcos, Madrid, Sílex, 2012: 297-328.

Baudot Monroy, M., La defensa del Imperio. Julián de Arriaga en la Armada, Madrid, Ministerio de Defensa, 20i2b.

Baudot Monroy, M., «La Hacienda de Marina entre la neutralidad de Fernando VI y la movilización de Carlos Ill en I76o», A. J. Rodríguez Hernández, J. Julio Arroyo, J.A. Sánchez, (eds.) Comercio, guerra y finanzas en una época de transición (siglos XVII y XVIII), Valladolid, Castilla Ediciones, 20I7: 195-224.

Bernal, A. M., «La Carrera del Pacífico: Filipinas en el sistema colonial de la Carrera de Indias», en L. Cabrero (ed), España y el Pacífico, Madrid, Sociedad Estatal de Conmemoraciones Culturales, tomo I, 2004: 485-452.

BJork, C., «The Link that Kept the Philippines Spanish: Mexican Merchant Interests and the Manila Trade, I57I-I8I5», Journal of World History, 9 (2009): 25-50.

Bonialian, M., El Pacífico hispanoamericano. Política y comercio asiático en el Imperio español (I680-I784), México, El Colegio de México, 2012.

Boxer, C., «War and Trade in the Indian Ocean and the South China Sea, I60o-I650», Mariner's Mirror, 7I (I985): 4I7-436. 
Burgos Madroñero, M., «La Matrícula de Mar en Andalucía. Siglos XVIII y XIX», en II Congreso de Historia de Andalucía, Córdoba, I99I.

Brand, D. D., «The Development of the Pacific Coast Ports during the Spanish colonial Period in Mexico», en Juan Comas (ed), Estudios antropológicos publicados en honor al Doctor Manuel Gamio. México, UNAM, 1956: 577-59I.

Calairo, E. F., «Building the Galleons: Some Preliminary Notes on Philippine Shipbuilding during the Spanish Period», en Probing Philippine-Spanish Connections in History, Manila, National Historical Commisision of the Philippines, 2012: 69-80.

CALvo, T., Espacios, climas y aventuras: el galeón de Filipinas y la fragata de las Marianas (I680I700). México, COLSAN, 2016.

Castillo Manrubia, P., La Marina de Guerra española en el primer tercio del siglo XIX, Madrid, Ed. Naval, 1992.

Clayton, L., Caulkers and Carpenters in a New World, Athens, University Center for International Studies, I980.

Craig, A. y Benítez, C., Philippine Progress Prior to I898, Manila, Philippine Education Company, igi6.

Cummins, J. S. y Cushner, N. P., «Labor in the Colonial Philippines: the Discurso Parenetico of Gomes de Espinoza», Philippine Studies, 22, No I-2 (I974): II7-203.

Erkoreka, J. I., Análisis histórico-institucional de las cofradías de mareantes del País Vasco. Vitoria-Gasteiz, Servicio Central de Publicaciones del Gobierno Vasco, I99I.

FadriQuela, C. S., Wood in the Philippines. Manila, University of Santo Tomas Publishing House, 2013, 2 vols.

FERNÁNDEZ IZQUieRdo, F., «Astilleros y construcción naval en la España anterior a la Ilustración», en España y el ultramar hispánico hasta la Ilustración. Cuadernos Monográficos del Instituto de Historia y Cultura Naval, tomo I, I989: 35-6I.

FERRET, Z., Exposición histórica de las causas que más han influido en la decadencia de la marina española e indicación de algunos medios para restaurarla, escrita en I813, Barcelona, Roca y Gaspar, I8I9.

Franco Castañón, H., «La organización de la marina en Filipinas. Acaecimientos y evolución (1800-I899)», en La Marina en Filipinas. Cuadernos Monográficos del Instituto de Hstoria y Cultura Naval, 66 (2012): 45-102.

García del Valle Gómez, J., Retrato de un navió. Nuestra Señora del Pilar de Zaragoza, de la carrera de Manila-Acapulco (I733-I750), Madrid, Editorial Naval, I993.

GARCía FeRnÁNDEZ, E. «Las cofradías de mercaderes, mareantes, y pescadores vascas en la Edad Media», en B. Arízaga, y J. A. Solórzano (Ed.), Ciudades y villas portuarias del Atlántico en la Edad Media, Nájera, 2004: 257-29.

Gaztañeta, A. De, Proporciones de las medidas mas essempciales, Madrid, Phelipe Alonso, 1720.

Glete, J., Navies and Nations. Warships, Navies and state Building in Europe and America, I500-I860, Estocolmo, Almqvist \& Wiskell, I993, 2 vols.

Glete, J., War and the State in Early Modern Europe. Spain, the Dutch Republic and Sweden as Fiscal-Military States, I500-I660, London, Routledge, 2002.

GonZÁlez EnCiso, A., «Los gremios y el crecimiento económico», Memoria y Civilización, Anuario de Historia, I, (I998): III-I37.

GonZÁlEZ EnCISO, A., «La promoción industrial en la España moderna: intervención pública e iniciativa privada», en Ribot García y De la rosa, 1. (eds.), Industria y época moderna. Madrid, Actas, 2000: 15-46.

GonZÁlezZ ENCISO, A., «Asentistas y fabricantes: el abastecimiento de armas y municiones al Estado en los siglos XVIl y XVIll», Studia histórica, Historia moderna, 35, (2013): 269-303. 
Hoces-García, A., «La Matrícula del Mar en el departamento marítimo de Cartagena durante el siglo XVIII: una complicada aplicación», Mediterranea. Ricerche Storiche, XII, (2015): 539-558.

Hidalgo Nuchera, P., Encomienda, trabajo y tributo en Filipinas (I570-I608), Madrid, Universidad Autónoma de Madrid-Ediciones Polifemo, 1995.

LANG, M., Las flotas de la Nueva España (I630-I7IO). Despacho, azogue, comercio, SevillaBogotá, Muñoz Moya Editores, 1998.

Laviana Cuetos, M. A., «La maestranza del astillero de Guayaquil en el siglo XVIIl», Temas Americanistas 4, (I984): 74-9I.

López Gómez, M. y Mirabet Cucala, M., «La institucionalización de la Matrícula de Mar: textos normativos y consecuencias para la gente de mar y maestranza», en C. Martínez Shaw, (ed.), El Derecho y el Mar en la España Moderna, Granada, Universidad de Granada, I995: 217-239.

Llovet, J., La Matrícula de Mar i la provincia de Marina de Mataró al segle XVIII, Mataró, Dalmau, I980.

Maıso GonZÁLEZ, J., La difícil modernización de Cantabria en el siglo XVIII, Santander, Estudio, I990.

MARLEY, D. F., «The Last Manila Galleon», en Warship, Londres, Conway Maritime Press, I99I.

Marley, D. F., «The Great Galleon: The Santisima Trinidad (1750-1765) », Philippine Studies, 4I/ 2 (I993): I67-I8I.

Martínez Shaw, C. y Alfonso Mola, M., «La introducción de la Matrícula del Mar en Indias», en C. Martínez Shaw y J. M. Oliva Melgar (eds.), El sistema atlántico español (siglos XVII-XIX), Madrid, Marcial Pons, 2005: 27I-284.

Martínez Shaw, C. y Alfonso Mola, M., «Los astilleros de la América colonial», en A. Castillero Calvo y A. Kuethe (coords.), Historia General de América Latina, Vol. 3, Tomo I, I999: 279-304.

Martínez Shaw, C. y Alfonso Mola, M., «The Philippine Islands: a vital crossroads during the first globalization period», Culture \& History Digital Journal, (2014): 6-I6.

Martínez Shaw, C. y Fernández Díaz, R., «Las Revistas de Inspección de la Matrícula de Mar en el siglo XVIII», en C. Martínez Shaw (ed.), El Derecho y el Mar en la España Moderna, Granada, Universidad de Granada, I995: 243-27I.

MCCARThY, W. J., «The Shipyards at Cavite: Shipbuilding in the Early Colonial Philippines», International Journal of Maritime History, 7/ 2 (I995): I49-I62.

Mestre Prat de Padua, M., «La construcción naval de guerra en la España del siglo XVIII. El marco legal de los procesos de financiación», en C. Martínez Shaw (ed,), El derecho y el mar en la España moderna, Granada, Universidad de Granada, I995: 299-322.

Molas, P., «Los gremios y la industria en la época moderna» en L. Ribot García y L. De la Rosa, (eds.), Industria y época moderna, Madrid, Actas, 2000: 15-46.

Mühlmann, R., Die Reorganisation der Spanischen Kriegsmarine in I8 Jahrhundert, ColoniaViena, I975.

O’Dogherty, A., «La Matrícula de Mar en el reinado de Carlos Ill», Anuario de Estudios Americanos, IX, (1952): 347-370.

Ortiz Sotelo, J., La Real Armada en el Pacífico sur: el apostadero Naval del Callao, I746-I824, México, Bonilla Artigas-IIH-UNAM, 2015.

Pinzón Ríos, G., Acciones y reacciones en los puertos de la Mar del Sur. Desarrollo portuario del Pacífico novohispano a partir de sus políticas defensivas, I7I3-I789, México, UNAM/ Instituto Mora, 20II. 
Quintero GonzÁLEZ, J., La Carraca: el primer arsenal ilustrado español (I7I7-I776), Madrid, Ministerio de Defensa, 2004.

Radell, D. R. y PARsons, J. J., «El Realejo: A Forgotten Colonial Port and Shipbuilding Center in Nicaragua», The Hispanic American Historical Review, 5I, (I971): 295-312.

Rahn Phillips, C., Six Galleons for the King of Spain. Imperial Defense in the Early Seventeenth Century, Baltimore, John Hopkins University Press, I992.

Rahn Phillips, C., «The Labor Market for Sailors in Spain I570-I870», en Van royen, P. C., Brujin, J. y Lucassen, J., Those Emblems of Hell?: European Sailors and the Maritime Labour Market, Liverpool, University Press, 2017: 329-48.

Roda AlCANTUd, C., «La maestranza naval en los arsenales españoles: siglos XVIII-XIX», Tiempo y Espacio, 23/64, (2015): 317-330.

SAlas, J. DE, Historia de la Matrícula de Mar y examen de varios sistemas de reclutamiento marítimo, Madrid, Fortanet, I870.

SAlAZAR, L. M., Juicio crítico sobre la marina militar de España dispuesto en la forma de cartas de un amigo a otro, Ferrol, Rocardo Pita, 1888.

SAlES Colin, O., «Polistas y arquitectura naval: una polémica contra los recursos de la tierra filipina durante el siglo XVII», Revista de Historia Naval 3I (20I3): 59-76.

Santana, J. M., «La Matrícula del Mar y el Banco Sahariano», Espacio, Tiempo y Forma. Historia Moderna 22 (2009): I5I-I66.

SEgura Obrero, J., «El gremio de pescadores y mareantes de Cartagena y la reforma marítima de Godoy (I786-180o)», Anales de Historia Contemporánea, 6 (I987): 39-59.

Serna VAllejo, M., De los gremios de mareantes a las actuales cofradías pesqueras de Castro Urdiales, Colindres, Laredo y Santoña, Santander, Universidad de Cantabria, 2016.

Serrano Álvarez, J. S., El astillero de La Habana y la construcción naval, I70O-I750, Madrid, Ministerio de Defensa, 2008.

VAldez-Bubnov, I., «Los inicios del astillero de la Habana y la influencia francesa», História (São Paulo) 30/I (20II): 287-305.

VALDEZ-Bubnov, I., «El poder y la gloria: élites y asientos militares en el astillero de La Habana durante el siglo XVIII», Studia Histórica, 35 (2013): 99-I25.

Solórzano Telechea, J. A., «Las ordenanzas de la Cofradía de Mareantes de San Vicente de la Barquera (I330-I537)», AHDE, tomo LXXXI, (20II): I030-I048.

Storrs, C., The Resilience of the Spanish Monarchy, I665-I700, Oxford, Oxford University Press, 2006.

Tena García, M. S., «Composición social y articulación interna de las cofradías de pescadores y mareantes», Espacio, Tiempo y Forma. Historia Medieval 8 (I995): III-I34.

Thompson, I. A.A., Guerra y decadencia. Gobierno y administración en la España de los Austrias, I560-I620, Barcelona, Crítica, I98I.

Thompson, I. A.A., «Navies and State Formation: The Case of Spain (I500-I80o) », en Backhaus, J., (ed). Navies and State Formation: The Schumpeter Hypothesis Revisited and Reflected, Vienna and Berlin, Lit Verlag, 2012: 317-35I.

Thurmann, M. E., The Naval Department of San Blas. New Spain's Bastion for Alta California and Nootka from I767 to I798, Glenadale, Arthur and Clarck, I967.

Torres SÁnchez, R., «Producir o comprar: la demanda de la corona española de productos industriales en el siglo XVIII», en L. Ribot y L. De La Rosa (eds.), Industria y Época Moderna, Madrid, Actas, 2000: 95-I32.

Torres SÁnchez, R., «Administración o asiento: la política estatal de suministros militares en la monarquía española del siglo XVIII», Studia histórica, 35, (2013): 159-I99. 
TORRES SÁNCHEZ, R., Military Entrepreneurs and the Spanish Contractor State in the Eighteenth Century, Oxford, Oxford University Press, 2016.

VALDEZ-BUBNov, I., «El conflicto Sevilla-Cádiz y la construcción naval española, I607-I725», Derroteros del Mar del Sur, I7, (2009a): 85-104.

Valdez-Bubnov, I., «War, Trade and Technology: The Politics of Spanish Shipbuilding Legislation, I607-1728», International Journal of Maritime History, 21/2, (2009b): 75-102.

VALDEZ-BuBnov, I.,Poder naval y modernización del Estado: política de construcción naval española (siglos XVI-XVIII), México, IIH-UNAM/ Bonilla Artigas / Iberoamericana Vervuert, 2oII.

VALDEZ-Bubnov, l., «El navío de 70 cañones de González Cabrera Bueno (I734): ¿un modelo tecnológico propio de la carrera de Filipinas?», en Relaciones intercoloniales: Nueva España y Filipinas, Zapopan, COLJAL, 2017a: 63-88.

VALDEZ-BuBnOV, l., «Comercio, guerra y tecnología: la construcción naval para la carrera de Filipinas (I577-I757)», en A.J. Rodríguez Hernández, J. Arroyo y J.A. Sánchez (eds.), Comercio, Guerra y Finanzas en una época de transición, (siglos XVII-XVIII), Valladolid, Castilla Ediciones, 20I7b: 225-270.

VALDEZ-Bubnov, l., «Shipbuilding administration under the Spanish Habsburg and Bourbon regimes (I590-I834): A comparative perspective», Business History, 60/I (2018): I05-I25.

VÁzQUEZ LıJó, J. M., «La matrícula de mar y sus repercusiones en la galicia del siglo XVIII», Obradoiro de Historia Moderna, 15, (2006): 289-322.

VÁzQuez LıJó, J. M., La matrícula del mar en la España del siglo XVIII. Registro, inspección y evolución de las clases de marinería y maestranza, Madrid, Ministerio de Defensa, 2007.

ILA MirANDA, C., «Arsenales españoles de ultramar en el siglo XVIII» en: España y el ultramar hispánico hasta la Ilustración. Cuadernos Monográficos del Instituto de Historia y Cultura Naval, 4I, (2002): 4I-57.

Yuste, C., El comercio de la Nueva España con Filipinas, I570-I785, México, INAH, I984.

Yuste, C., «De la libre contratación a las restricciones de la permisión. La andadura de los comerciantes de México en los giros iniciales con Manila, I580-I6ı»», en C. Martínez Shaw y S. Bernabeu (eds.), Un océano de seda y plata: el universo económico del Galeón de Manila, Sevilla, CSIC, 20I3: 85-Io6. 

Monográfico - Special Issue: Política imperial y administración de industrias estratégicas: la Armada española en el largo siglo XVIII Imperial Policy and Strategic Industry Administration: the Spanish Navy in the Long Eighteenth Century

María Baudot Monroy, Manuel Díaz-Ordóñez \& IVÁN VALDEZ-BUbnov

Introducción / Introduction

\section{Agustín González Enciso}

Estado y empresa en la provisión de armas de fuego en el Siglo XVIII / State and Enterprises in the Supply of Firearms in the Eighteenth Century

\section{Manuel Díaz-Ordóñez}

El abastecimiento militar de cáñamo para el imperio español (16651808): globalización, estado y empresarios en el largo Siglo XVIII / Providing Hemp for Military Purpose for the Spanish Empire (1665-1808): Globalization, State and Entrepreneurs in the Long Eighteenth Century

\section{RAFAL B. REICHERT}

¿Cómo España trató de recuperar su poderío naval? Un acercamiento a las estrategias de la marina real sobre los suministros de materias primas forestales provenientes del Báltico y Nueva España (1754-1795) / How did Spain Tried to Recover his Naval Power? An Approach to the Strategies of the Royal Navy on the Supply of Forest Raw Materials from Baltic Sea and New Spain (1754-1795)

\section{José Manuel Vázquez Lijó}

Servir en la marina de Aranjuez en el Siglo XVIII: un destino deseado / Serving in the Navy in Aranjuez in the $18^{\text {th }}$ Century: A Desirable Destination

\section{IVÁN VALDEZ-BUBNOV}

Navíos para un imperio global: la construcción naval y la matrícula de mar en España, América y Filipinas durante el largo Siglo XVIII (1670-1834) / Warships for a Global Empire: Shipbuidling and the Maritime Registry in Spain, America and the Philippines during the Long Eighteenth Century (1670-1834)

\section{MARIA BAUdot MONROY}

La construcción de la Real Armada en Filipinas. Marinos españoles en Manila en la segunda mitad del siglo XVIII / Constructing the Spanish Royal Navy in the Philippines. Navy Officers in Manila during the Second Half of the Eighteenth Century

\section{Miscelánea · Miscellany}

\section{IVÁN LÁZARO URDIALES}

Las relaciones entre España y Rusia durante el reinado de Felipe V (1722-1742) / Relationships between Spain and Russia during the Reign of Philip V (1722-1742

\section{LEOPOLDINA LANDEROS DE CASOLARI \\ Controversias sobre el cosmógrafo Andrés García de Céspedes /} Controversies about the Cosmographer Andrés García de Céspedes

\section{Ainoa Chinchilla Galarzo \\ Portugal y la fallida paz con Francia: mediación española y corrupción francesa (1796-1800) / Portugal and the Failed Peace with France: Spanish} Mediation and French Corruption (1796-1800)

\section{Marcos Rafael Cañas Pelayo}

De una compañía comercial a la inserción en la élite cordobesa: los Fernández de Carreras (S. XVI-XVIII) / From a Trade Company to the Insertion in the Cordovan Elite: Fernández de Carreras's Lineage $\left(16^{\text {th }}-18^{\text {th }}\right.$ Centuries)

\section{Rumen Sosa Martín}

La sustitución lingüística del guanche en las Islas Canarias, un caso excepcional en la historia del mundo bereber / The Language Shift of Guanche Language in the Canary Islands, an Exceptional Case in the History of the Berber's World

\section{Aitor Díaz Paredes}

Fidelidad, fueros y negociación. Las Cortes de Sangüesa en la defensa de la Corona de Aragón (1705) / Loyalty, Fueros and Negotiation. The Cortes of Sangüesa in the Defense of the Crown of Aragon (1705)

\section{Taller de historiografía · Historiography Workshop}

\section{Ensayos · Essays}

\section{David Martín Marcos \\ La otra mirada de António Manuel Hespanha (1945-2019), In Memoriam /} An Alternative Gaze: António Manuel Hespanha (1945-2019), In Memoriam

333 Gabriel Astey

Virtud de la retorsión / Nobility of Contortion 


\section{Reseñas · Book Review}

345 Burke, Peter Hybrid Renaissance. Culture, Language, Architecture (ANTONIO URQUízar HeRRERA)

351 OLDS, Katrina B., Forging the past. The Invented Histories in Counter-Reformation Spain (JAVIER RodRíguez Solís)

357 Bolufer Peruga, Mónica, Mujeres y Hombres en la Historia. Una propuesta historiográfica y docente (JuLıo ARroyo VozMEDIANO)

361 Mira Caballos, Esteban, Francisco Pizarro. Una nueva visión de la conquista del Perú, (BeAtriz Alonso Acero)

367 Esteban Estríngana, Alicia (ed.), Decidir la lealtad. Leales $y$ desleales en contexto (siglos XVI-XVII) (José MigueL ESCRIBANO PÁEZ)

371 GaUdin, Guillaume, El Imperio de papel de Juan Díez de la Calle. Pensar y gobernar el Nuevo Mundo en el siglo XVII (JAVIER RUIZ IBÁÑEZ)

375 PASOLINI, Alessandra y PILO, Rafaella (eds.), Cagliari and Valencia during the Baroque Age. Essays on Art, History and Literature (FERNANDO CIARAMITARO)

381 SÁnCHEZ-Montes GonzÁLEz, Francisco, El viaje de Felipe IV a Andalucía en 1624. Tiempo de recursos y consolidación de lealtades (Francisco PREcioso IzQUiERDo)

385 Alimento, Antonella \& Stapelbroek, Koen (eds.), The Politics of Commercial Treaties in the Eighteenth Century: Balance of Power, Balance of Trade (FIDEL J. TAVÁREZ)

393 Marchena Fernández, Juan y Cuño Bonito, Justo (eds.), Vientos de guerra. Apogeo y crisis de la Real Armada (Pablo Ortega del Cerro) 